\title{
Macedonian International Medical Publications Indexed in PubMed in 2011
}

\author{
Macedonian Journal of Medical Sciences \\ Institute of Immunobiology and Human Genetics, Faculty of Medicine, University "Ss Cyril and Methodius", Skopje, Republic of \\ Macedonia
}

\begin{abstract}
Citation: Macedonian Journal of Medical Sciences. Macedonian International Medical Publications Indexed in PubMed in 2011. Maced J Med Sci. 2012 Jul 31:5(2):222-252 http://d x. do i. org/10.3889/M JMS 1857 doi.org/10.3889/M JM S.1857

Key words: Medical Publications; Medical research; Republic of Macedonia.

Correspondence: Macedonian Journal of Medical Sciences. Institute of Immunobiology and Human Genetics, Faculty of Medicine, University "Ss Cyril and Methodius", Skopje, Republic of Cyril and 50 Divizija No 16, PO Box 60,1109 Macedonia. 50 Diviza No 16, B Box 60, 1109 2 3110556. Telefax: +389 23110558 . EMail: mjms@ukim.edu.mk

Received: 12-Jun-2012; Revised:20-Jun-2012; Accepted: 30-Jun-2012; Online first: 03-Jul-2012

Copyright: $\odot 2012$ Macedonian Journal of Medical Sciences. This is an open-access article distributed under the terms of the Creative Commons Attribution License, which permits unrestricted use, distribution, and reproduction in any medium, provided the original author and source are credited.

Competing Interests: The author have declared that no competing interests exist.
\end{abstract}

\section{Abstract}

We present abstracts of published papers in international journals deposited in PubMed between 201101-01 and 2011-12-31 from the scientists affilited in institutions from the Republic of Macedonia[(Macedonia[Affiliation]) NOT [(Greece[Affiliation]) NOT (Prilozi[Jour])] (searched July 1 , 2012). English summaries are published as they are deposited by PubMed.

A total number of 86 papers were indexed in PubMed during 2011 year [77 papers from 2011 and 9 papers from 2012 (ahead of print)].

Three papers (Gucev Z, Ristoska-Bojkovska N, Popovska-Jankovic K, Sukarova-Stefanovska E, Tasic V, Plaseska-Karanfilska D, Efremov GD. Cystinuria AA (B): digenic inheritance with three mutations in two cystinuria genes. J Genet. 2011 Apr;90(1):157-9; Jakovski Z, Nikolova K, Jankova-Ajanovska R, Janeska B, Pojskic N, Marjanovic D. Allele frequencies of the new European Standard Set (ESS) loci plus SE33 locus in a population from the Republic of Macedonia. Forensic Sci Int Genet. 2012 May:6(3):e90-2. Epub 2011 Jul 28; Tasic V, Lozanovski VJ, Gucev Z, Blau N, Cheong HI, Sayer JA. Failure to thrive and nephrolithiasis in a boy with congenital cyanotic heart anomaly. Pediatr Nephrol. 2011 Dec;26(12):2153-7. Epub 2011 Mar 1.) are without abstract.

Editorial Board does not take any responsibility either for the content, nor the quality of the abstracts.
Antevski B, Jovkovski O, Filipovski V, Banev S. Extreme gigantomastia in pregnancy: case report-my experience with two cases in last 5 years. Arch Gynecol Obstet. 2011 Sep;284(3):575-8. Epub 2010 Oct 27.

Clinic for Thoracic and Vascular Surgery, Clinical Center, University of "Ss. Cyrill and Methodiuos" Skopje, "Vodnjanska bb", 1000 Skopje, Republic of Macedonia.

\section{borceantevski@yahoo.com}

We present an extreme case of gigantomastia in pregnancy during the second gemelar pregnancy of a 30-year-old woman. Her first pregnancy was 8 years ago, was also gemelar and she delivered with caesarean section. From the beginning of her current pregnancy, the patient noted steady growth of both of her breasts that reached enormous dimensions at the end of the 
pregnancy. This kind of breast changes did not occur during her first pregnancy. The patient also suffered from myasthenia gravis that was in remission during this pregnancy, without any therapy. The patient was in the 38 weeks of gestation, and a delivery with caesarean section was performed in line with the reduction of her breasts. The main reasons that led me to perform these two interventions as one act were the fact that puerperal mastitis could develop on these enormous breasts, further the small regression of these huge breasts during the bromocriptine treatment, as well as the intention to avoid other operative traumas, considering possibility of exacerbation of myasthenia gravis. I had already performed bilateral reduction mammaplasty with free areola-nipple graft, when a tissue with total weight of 20 $\mathrm{kg}(2 \times 10 \mathrm{~kg})$ was removed. The patient had an excellent post-operation recovery course. PMID: 20978777

Antovska SV, Bashevska N, Aleksioska N. Predictive values of the ultrasound parameters, CA-125 and risk of malignancy index in patients with ovarian cancer. Klin Onkol. 2011;24(6):435-42.

Department for Urogynaecology and Pelvic Floor Disorders, University Clinic for Gynaecology and Obstetrics, Medical Faculty, University Saint Cyril and Methodius, Skopje, Republic of Macedonia. vantovska@yahoo.com

BACKGROUNDS: Assessment of predictive values for CA-125, ultrasound features (US) and risk of malignancy index (RMI) in ovarian malignancy. MATERIAL AND METHODS: 115 patients, divided into: 1$)$ group- $A(n=$ 41)_ovarian malignancy; group- $B(n=74)$-benign ovarian tumor; 2 ) subgroup-CA(a) with low CA-125 ( $<35$ $\mathrm{U} / \mathrm{mL})(\mathrm{n}=64)$; subgroup-CA(b) with slightly elevated CA-125 (35-130 U/ml) $(\mathrm{n}=26)$; subgroup-CA(c) with high CA-125 (> $130 \mathrm{U} / \mathrm{ml})(\mathrm{n}=25)$. RESULTS: 1$)$ patients of group-A were older $(p<0.05)$; CA- $125<35$ $\mathrm{U} / \mathrm{ml}$ predominated in group-B $(p<0.001) ; 2)$ CA-125 < $35 \mathrm{U} / \mathrm{ml}$ showed relatively high NPV, sensitivity and specificity (82.8\%; 0732; 0.716, respectively). Our proposed graduation of CA-125 into three grades: a) < $35 \mathrm{U} / \mathrm{mL}$; b) $35-130 \mathrm{U} / \mathrm{mL}$; c) $>130 \mathrm{U} / \mathrm{mL}$ increased the specificity for both parameters: CA125 $=35-130 \mathrm{U} / \mathrm{mL}$ up to 0.811 , and for CA-125>130 U/mL up to 0.905 , and PPV for the latter parameter up to $72.0 \%$; 3) US: a) highest sensitivity, as indicator for best distinguishing of diseased patients, showed: rugged margins and presence of septum/vegetations $(0.878 ; 0.897$, respectively); b) highest specificity, as indicator for best distinguishing of healthy patients: clear distinguish ability of tumor from surrounding tissue and absence of ascites (0.811; 0.932, respectively); c) presence of ascites had highest PPP (100\%) i.e. it was the best malignancy predictor; 4) RMI showed only relatively high NPV for $\mathrm{RMI}<$ or $=200$ (76.8\%); 4) additional analysis of RMI in correlation with proposed CA-125 gradation increased the predictive values of RMI: a) subgroup-CA(a): NPV and sensitivity for $\mathrm{RMI}<$ or $=200$ (81.6\%; 0.818, respectively) and NPV for RMI > $200(86.7 \%)$; b) subgroup-CA(b): specificity for $\mathrm{RMI}<$ or $=200$, as good indicator for distinguishing healthy patients (0.929); c) subgroup-CA(c): sensitivity for RMI > 200, as good indicator for distinguishing diseased patients (0.944). CONCLUSION: CA-125 and US, as single criteria were not accurate. RMI is good indicator only in correlation with CA-125. PMID: 22257232

\section{Atanasovska-Stojanovska A, Trajkov D, Nares S, Angelov N, Spiroski M. IL4 gene polymorphisms and their relation to periodontal disease in a Macedonian population. Hum Immunol. 2011 May;72(5):446-50. Epub 2011 Feb 25.}

Dental Clinical Center, Department of Oral Pathology and Periodontology, Faculty of Stomatology, University Ss. Kiril and Metodij, Skopje, Republic of Macedonia.

Genetic polymorphisms in the interleukin-4 (IL4) gene have been reported to influence the host response to microbial challenge by altering levels of cytokine expression. We analyzed nucleotide polymorphisms in the promoter region of the IL4 gene and its relation with periodontal disease in a Macedonian population. The study population consisted of 92 unrelated subjects with chronic periodontitis and 286 healthy controls. DNA was isolated and IL4 genotyping performed by polymerase chain reaction-single-strand polymorphism (Heidelberg kit) for the alleles and genotypes of IL4 -1098, IL4 -590, and IL4 -33. Frequencies of IL4 haplotypes and the haplotype zygotes were also examined. Comparisons between groups were tested using the Pearson's $p$ value. After Bonferroni adjustment, significant associations were detected between subjects with periodontitis and the following: (1) cytokine alleles IL4 1098 and IL4 -33; (2) cytokine genotypes IL4 -1098/G:T; IL4 -1098/T:T, and IL4 -33/T:T, (3) cytokine haplotypes IL4/GCC, IL4/TCC, and IL4/TTC; and (4) cytokine haplotype zygotes IL4/TTC: TCC, IL4/TCT:TTT, and IL4/GCC:TTC. Cytokine polymorphism on the IL4 gene appears to be associated with susceptibility to chronic 
periodontitis in Macedonians. PMID: 21354455

Balabanova B, Stafilov $\mathrm{T}$, Sajn R, Baèeva $\mathrm{K}$. Distribution of chemical elements in attic dust as reflection of their geogenic and anthropogenic sources in the vicinity of the copper mine and flotation plant. Arch Environ Contam Toxicol. 2011 Aug;61(2):173-84. Epub 2010 Sep 22.

Faculty of Agriculture, Goce Delèev University, P.O. Box 201, 2000, Š tip, Macedonia.

The main aim of this article was to assess the atmospheric pollution with heavy metals due to copper mining Buèim near Radoviš , the Republic of Macedonia. The open pit and mine waste and flotation tailings are continually exposed to open air, which leads to winds carrying the fine particles into the atmosphere. Samples of attic dust were examined as historical archives of mine emissions, with the aim of elucidating the pathways of pollution. Dust was collected from the attics of 29 houses, built between 1920 and 1970. Nineteen elements (Ag, Al, As, $\mathrm{Ba}, \mathrm{Ca}, \mathrm{Cd}, \mathrm{Co}, \mathrm{Cr}, \mathrm{Cu}, \mathrm{Li}, \mathrm{Fe}, \mathrm{K}, \mathrm{Mg}, \mathrm{Mn}, \mathrm{Na}, \mathrm{Ni}, \mathrm{Pb}, \mathrm{Sr}$, and $\mathrm{Zn}$ ) were analyzed by atomic emission spectrometry with inductively coupled plasma. The obtained values of the investigated elements in attic dust samples were statistically processed using nonparametric and parametric analysis. Factor analysis revealed three factors governing the source of individual chemical elements. Two of them grouping $\mathrm{Ca}, \mathrm{Li}, \mathrm{Mg}, \mathrm{Mn}$, and $\mathrm{Sr}$ (Factor 1) and $\mathrm{Co}, \mathrm{Cr}$, and $\mathrm{Ni}$ (Factor 2) can be characterized as geogenic. The third factor grouping As, $\mathrm{Cu}$, and $\mathrm{Pb}$ is anthropogenic and mirrors dust fallout from mining operation and from flotation tailings. Maps of areal deposition were prepared for this group of elements, from which correlation of these anthropogenic born elements was confirmed. PMID: 20859621

\section{Bosevski M. Diabetic angiopathy. Angiol Sosud Khir.} 2011;17(4):14-23.

University Cardiology Clinic, Medical Faculty Skopje, Macedonia.marijanbosevski@yahoo.com

Peripheral arterial disease is high prevalent in patients with diabetes mellitus. The purpose of this review article is to resume ethiogenesis, diagnostic methodology and treatment modalities of this condition, also known as diabetic angiopathy. PMID: 22616224
Brezovska K, Panovska AP, Grozdanova A, Suturkova L, Basta I, Apostolski S. Immunoreactivity of glycoproteins isolated from human peripheral nerve and Campylobacter jejuni (0:19). J Neurosci Rural Pract. 2011 Jul;2(2):125-9.

Faculty of Pharmacy, University Ss. Cyril and Methodius, Skopje, Macedonia.

OBJECTIVE: Antibodies to ganglioside GM1 are associated with Guillain-Barré Syndrome (GBS) in patients with serologic evidence of a preceding infection with Campylobacter jejuni. Molecular mimicry between C. jejuni Lipopolysaccharide (LPS) and ganglioside GM1 has been proven to be the immunopathogenic mechanism of the disease in the axonal variant of GBS. GM1-positive sera cross-react with several GalGalNAcbearing glycoproteins from the human peripheral nerve and $C$. jejuni (O:19). This study aimed to examine the simultaneously at age 14 years, and GTCS occurred one year later. The proband's mother had her first seizures at the age of 39 years (brief myoclonic jerks and subtle absences predated GTCS by a few months). In the second family, the proband and his younger brother presented with JME at the age of 13 years, their mother experienced a single GTCS at the age of 38 years, while the grand-mother died during de novo generalised status at the age of 62 years. To our knowledge, this is one of the few reports to describe the occurrence of possible genetic anticipation in IGE which should be further investigated in larger cohorts of patients. PMID: 21636347

Chorbev I, Sotirovska M, Mihajlov D. Virtual communities for diabetes chronic disease healthcare. Int J Telemed Appl. 2011;2011:721654. Epub 2011 Nov 3.

Faculty of Computer Science and Engineering, Ss. Cyril and Methodius University in Skopje, P.O. BOX 574, 1000 Skopje, Macedonia.

Diabetes is classified as the world's fastest-growing chronic illness that affects millions of people. It is a very serious disease, but the bright side is that it is treatable and can be managed. Proper education in this view is necessary to achieve essential control and prevent the aggregation of this chronic sickness. We have developed a healthcare social network that provides methods for distance learning; opportunities for creation of virtual self-help groups where patients can get information and establish interactions among each other in order to exchange important healthcare-related information; 
discussion forums; patient-to-healthcare specialist communication. The mission of our virtual community is to increase the independence of people with diabetes, self-management, empower them to take care of themselves, make their everyday activities easier, enrich their medical knowledge, and improve their health condition, make them more productive, and improve their communication with other patients with similar diagnoses. The ultimate goal is to enhance the quality of their life. PMCID: PMC3216370. PMID: 22121358

\section{Cvetkovska E, Panov S. Possible genetic anticipation in families with idiopathic generalised epilepsy. . Epileptic Disord. 2011 Jun;13(2):150-4.}

University Clinic of Neurology, Ss Cyril and Methodius University, Skopje, Republic of Macedonia. emilicvet@yahoo.com

Idiopathic generalised epilepsies (IGE) constitute nearly one third of all epilepsies. IGEs manifest with absences, myoclonic jerks and generalised tonic-clonic seizures (GTCS), either alone or in varying combinations, and have a strong genetic background. We present two three-generation families with juvenile myoclonic epilepsy (JME) probands and other affected family members with different forms of IGE in whom genetic anticipation was possible, i.e. the progressive decrease in age at onset with each successive generation. In the first family, the proband presented with JME with all three seizure types with an age at onset of eight years. Her cousin presented with both absence seizures and myoclonic jerks simultaneously at age 14 years, and GTCS occurred one year later. The proband's mother had her first seizures at the age of 39 years (brief myoclonic jerks and subtle absences predated GTCS by a few months). In the second family, the proband and his younger brother presented with JME at the age of 13 years, their mother experienced a single GTCS at the age of 38 years, while the grand-mother died during de novo generalised status at the age of 62 years. To our knowledge, this is one of the few reports to describe the occurrence of possible genetic anticipation in IGE which should be further investigated in larger cohorts of patients. PMID: 21636347

Damevski V, Damevska G, Palasevska L, Nojkov O. Postoperative intrathecal analgesia for primary total hip arthroplasty-comparative clinical examination of two different small doses of morphium hydrochloride. BratisI Lek Listy. 2011;112(9):497-500.
Department of Anesthesiology, Reanimatology and Intensive medicine, Clinical Hospital Dr. Trifun Panovski, Bitola, R Macedonia.vladodamevski@yahoo.com

OBJECTIVE: To prospectively compare the spinal analgesia with two different small doses of morphium hydrochloride after primary total hip arthroplasty. BACKGROUND: In total hip arthroplasty, several techniques for postoperative analgesia can be used. In this study, we examined analgesia and side effects of intrathecal morphium hydrochloride (MCh) after primary total hip arthroplasty in small doses, namely $0.05 \mathrm{mg}$ and $0.1 \mathrm{mg}$. METHODS: Forty patients were randomized to receive either $0.5 \mathrm{ml} / 0.05 \mathrm{mg}$, or $0.5 \mathrm{ml} / 0.1 \mathrm{mg}$ of $\mathrm{MCh}$ intrathecally together with $3.5 \mathrm{ml}$ of $0.5 \%$ isobaric bupivacine hydrochloride. The duration of postoperative analgesia, the intensity of the initial pain sensation and the frequency of opioid side effects were recorded for the first 24 hours. RESULTS: The mean duration of analgesia in group M 0.05 was $14.3+/-1.1$ hours and was significantly shorter than $19.7+/-1.7$ hours in the M 0.1 group $(p<0.05)$. Visual analogue scale (VAS) score for the initial pain intensity in M 0.05 group was 5 (median value). That in M 0.1 group was 3 (median value). The difference was not significant $(p<0.05)$. There was no respiratory depression in the groups. The difference in the frequency of nausea and vomiting was not significant but that of itching was $(p<0.05)$. CONCLUSION: Intrathecal usage of $0.05 \mathrm{mg}$ and $0.1 \mathrm{mg}$ of $\mathrm{MCh}$ provides a long-lasting postoperative analgesia. It is a practical method to be provided after primary total hip arthroplasty. The efficacy of $0.1 \mathrm{mg}$ of MCh is greater compared to that of $0.05 \mathrm{mg}$ of MCh. These doses of MCh do not cause respiratory depression but cause nausea, vomiting and itching. PMID: 21954526

Damevski V, Damevska G, Krivasija M, Nojkov O, Sivevski A. Caesarean section in isobaric spinal anesthesia with and without direct preoperative hydration with crystalloids. Bratisl Lek Listy. 2011;112(8):459-62.

Department of Anesthesiology, Reanimatology and Intensive medicine, Clinical Hospital Dr Trifun Panovski, Bitola, R. Macedonia. genadamevski@gmail.com

BACKGROUND: Because the direct preoperative hydration with crystalloids $(20 \mathrm{ml} / \mathrm{kg}$ ) does not adequately prevent spinal hypotension during cesarean section, the authors investigated whether a continuous intravenous infusion of ephedrine (50 mg/500 ml of Ringer solution) without preoperative hydration would prevent the spinal 
hypotension more effectively. METHODS: Forty parturients with ASA status I were randomized either to receive a preoperative hydration with $20 \mathrm{ml} / \mathrm{kg}$ of Ringer solution, or to receive continuous ephedrine infusion, simultaneously with spinal anesthesia. The infusion rate was adjusted according to systolic blood pressure. Significant hypotension was defined as a systolic blood pressure below $100 \mathrm{mmHg}$. Rescue boluses consisted of ephedrine $10 \mathrm{mg}$ in parturients with prehydration and ephedrine $5 \mathrm{mg}$ in parturients with ephedrine infusion. RESULTS: Significant hypotension occurred less frequently in the ephedrine group than in the volume group: $40 \%$ versus $60 \%(p<0.05)$. Nausea and vomiting occurred less frequently in the ephedrine group than in the volume group: $40 \%$ and $30 \%$ versus $60 \%$ and $50 \%$, respectively $(p<0.05)$. The mean quantity of infused Ringer solution was $370 \mathrm{ml}+/-31$ in the ephedrine group, i.e. significantly lower than $1,640 \mathrm{ml}+/$ - 192 in the volume group $(p<0.05)$. The mean quantity of ephedrine given in the ephedrine group was $30 \mathrm{mg}+/$ - 4.1. The mean quantity of ephedrine given in the volume group was $25 \mathrm{mg}+/-2$. The difference was not significant. Apgar scores were similarly good in both groups. CONCLUSION: The continuous infusion of ephedrine simultaneously with spinal anesthesia is superior to direct preoperative hydration with crystalloids in preventing the spinal hypotension and its clinical manifestations in parturients delivered with $\mathrm{C}$-section. PMID: 21863617

Dervisevik M, Dinevska-Kjovkarovska S, Miova B, Mitev S, Velkovski M, Susleski D. Heat acclimationinduced changes in heart glycogen/glucose metabolism in rats. J Physiol Sci. 2011 Sep;61(5):395402. Epub 2011 Jul 10.

Department of Physiology and Biochemistry, Institute of Biology, Faculty of Natural Sciences and Mathematics, University St Cyrilus and Methodius, Gazi Baba bb, 1 000 Skopje, Republic of Macedonia. mirsadadervisevik@yahoo.com

Based on the observation that heat acclimation is a slowly developing response, evoked by continuous exposure to moderate heat, we investigated the timedependent acclimatory changes of heart glycogen metabolism. Cardiac levels of key carbohydrate-related enzymes and substrates were studied in the function of the duration of short-term (STHA; 6, 12, 24 and $48 \mathrm{~h}$ ) and long-term heat acclimation (LTHA; 7, 14, 21 and 30 days) to high environmental temperature $\left(35 \pm 1^{\circ} \mathrm{C}\right)$. The changes in heart glycogen metabolism during STHA could be separated in two phases: up to $12 \mathrm{~h}$ exposure, where significant decrease of the heart glycogen $(G l k)$, glucose-6-phosphate (G6P), hexokinase (HK) activity as well as increase of heart glucose was observed; and from 24 to $48 \mathrm{~h}$ exposure, manifested with elevation of Glk, Glu, glycogen phosphorylase a (GPa), phosphofructokinase (PFK) and HK activities. The metabolic changes in the period of LTHA could also be seen as separate phases: in a period of 7-14 days of heat exposure there was an increase of heart Glk, Glu, G6P, $\mathrm{HK}$, as well as a decrease of GPa and PFK, while in the period of 21-28 days there was more intensive rebound of Glk and G6P, increase of GPa activity and nonsignificant changes of Glu, HK and PFK. The results obtained have showed that acclimation to moderate hyperthermic environment has caused significant changes in examined parameters which differ depending on duration to the exposure: intensive stress-induced glycogenolytic and glycolytic processes in the period of STHA and intensive energy sparing, manifested by Glk deposition in the period of LTHA. PMID: 21744293

\section{Dimovska S, Stafilov T, Sajn R. Radioactivity in soil} from the city of Kavadarci (Republic of Macedonia) and its environs. Radiat Prot Dosimetry. 2012 Jan;148(1):107-20. Epub 2011 Feb 20.

Republic Institute for Health Protection, 50 Divizija 6, 1000 Skopje, Macedonia.

The activity concentrations and distribution of natural and anthropogenic radionuclides in soils from the city of Kavadarci, Republic of Macedonia, and its environs were investigated. The purpose of the study, the first of this kind in this region was to evaluate the environmental radioactivity and radiological health hazard, as well as to determine the connection between the concentration of natural radionuclides and the geology of the terrain. A total of 45 surface soil samples were collected from evenly distributed sampling sites. Gross alpha and gross beta activity measurements were made using a gas flow proportional counter, while the activity concentrations of gamma emitting radionuclides were measured using a high purity germanium detector. The average activity concentrations of t p K, ${ }^{22} \mathrm{~V} \mathrm{Ra},{ }^{22} \mathrm{Th}$ and ${ }^{1}{ }^{3} \mathrm{w}$ Cs were found to be $546 \pm 118,38.8 \pm 14.6,43.7 \pm 18.4$ and $41.5 \pm 40$ $\mathrm{Bq} \mathrm{kg}\left\{{ }^{1}\right.$, respectively. The mean values of gross alpha and gross beta activities were $522 \pm 192$ and $681 \pm 146 \mathrm{~Bq}$ $\operatorname{kg}\left\{{ }^{1}\right.$. The mean total absorbed dose rate in air calculated from the concentration of the natural radionuclides was 
$67.1 \pm 20.9$ nGy $h\{1$, and the corresponding annual effective dose rate outdoors was $0.082 \pm 0.026 \mathrm{mSv}$ y $\{1$. The results of the analysis show strong correlation between the abundance of the natural radionuclides in soils and their geological origin. PMID: 21335627

Dodevski A, Lazareska M, Tosovska-Lazarova D, Zhivadinovik J, Stojkoski A. Basilar artery fenestration. Folia Morphol (Warsz). 2011 May;70(2):80-3.

Institute of Anatomy, Medical Faculty, "Ss. Cyrill and Methodius University", Skopje, R. Macedonia. acedod@hotmail.com

The posterior circulation of the brain constitutes the vertebrobasilar system and its branches, which are responsible for about $30 \%$ of the brain's blood supply. The aim of this study was to describe the anomalies of the basilar artery, especially fenestrations. For that purpose, we examined 50 patients with computed tomography (CT) angiography during an 8-month period. In the CT reports of 2 (4\%) patients of the 50 analysed, fenestration was found at the proximal basilar trunk. The two fenestrations in our series were not associated with aneurysms. No collateral branches originated from the two limbs of the fenestration. In conclusion, basilar artery fenestrations are a rare finding. The data derived from this study are useful teaching material for anatomists, and for the radiologists and neurosurgeons they are important for diagnostic and intervention procedures such as CT, magnetic resonance imaging, angiography, and surgical and endovascular procedures. PMID: 21630227

Dzekova-Vidimliski P, Severova-Andreevska G, Trajceska L, Pusevski V, Selim G, Gelev S, Amitov V, Dzikova S, Sikole A. Aminotransferase activity as a poor predictor of liver disease progression in dialysis patients with chronic hepatitis C. Bratisl Lek Listy. 2011;112(10):568-71.

University Clinic of Nephrology, Skopje, R. Macedonia.

Lower aminotransferase activity in dialysis patients makes the assessment of the natural history of hepatitis $\mathrm{C}$ virus (HCV) infection difficult. The aim of the study was to determine the risk factors associated with the aminotransferase activity in dialysis patients with chronic hepatitis $\mathrm{C}$. According to the serum levels of alanine aminotransferase (ALT) during the follow-up, the patients were divided in the two groups. The first group consisted of 34 chronically HCV infected patients with persistently normal levels of ALT. The second group included 46 chronically HCV infected patients with elevated levels of ALT. Genotype 1 was the dominant genotype in both groups (78 patients, 97.5\%). Patients with the elevated ALT levels were characterized with a significantly shorter dialysis duration $(p=0.048)$ and a significantly shorter duration of HCV infection ( $p=0.005$ ) compared to the patients with persistently normal levels of ALT. The values of measured ultrasound parameters were not significantly different between the two groups. The univariate analysis identified a higher serum level of direct bilirubin $(p=0.044)$, shorter duration of dialysis $(p=0.048)$, and shorter duration of HCV infection $(p=$ $0.005)$ as potential predictors of elevated serum ALT levels in dialysis patients. After a stepwise logistic regression, none of the potential predictors was independently associated with the elevated ALT levels. Serum aminotransferase levels are poor predictors of liver disease progression in dialysis patients with chronic hepatitis C. Further studies should be conducted in order to identify non-invasive indicators of the disease progression in uremic patients with hepatitis C. PMID: 21954541

Gavrilova V, Kajdzanoska M, Gjamovski V, Stefova M. Separation, characterization and quantification of phenolic compounds in blueberries and red and black currants by HPLC-DAD-ESI-MSn. J Agric Food Chem. 2011 Apr 27;59(8):4009-18. Epub 2011 Mar 14.

Institute of Chemistry, Faculty of Natural Sciences and Mathematics, Ss. Cyril and Methodius University, Skopje, Republic of Macedonia.

The phenolic profile of four blueberry varieties (Vaccinium corymbosum L., cv. Toro, Legacy, Duke and Bluecrop) and two varieties (Rosenthal and Rovada) of red currants (Ribes rubrum L.) and black currants (Ribes nigrum L.) cultivated in Macedonia have been analyzed using HPLC coupled to diode-array detection and tandem mass spectrometry with electrospray ionization. A complex profile of anthocyanins, flavonols, flavan-3-ols and hydroxycinnamic acid derivatives has been assayed in acetone-acetic acid (99:1, v/v) extracts. Anthocyanins comprised the highest content of total phenolic compounds in currants (>85\%) and lower and variety dependent in blueberries (35-74\%). Hydroxycinnamic acid derivatives comprised $23-56 \%$ of total phenolics in blueberries and 1-6\% in currants. Chlorogenic acid was 
the major hydroxycinnamic acid in blueberries, only in the Legacy variety, two malonyl-caffeoylquinic acid isomers were major components. Flavonols, mainly quercetin and myricetin glycosides, were a minor group, but glucosides of laricitrin and syringetin were also detected in the blueberry varieties counting for $10-34 \%$ of total flavonols. From flavan-3-ols, catechin was detected in most samples; the dimer B2 was specific for blueberries whereas epigallocatechin was detected in currants. PMID: 21401099

Gerovski F. Compliance with international standards on patients' rights and implementation of the Law on the Protection of Patients' Rights in the Republic of Macedonia. Med Law. 2011 Jun;30(2):179-86.

Centre for Regional Policy Research and Cooperation Studiorum, Nikola Parapunov bb, Kompleks Makoteks, 1 kat, 1000 Skopje, Republic of Macedonia. filip.gerovski@studiorum.org.mk

In 2008, Macedonia adopted the Law on the Protection of Patients' Rights. This was a big step forward in the field of health care and regulation of patients' rights and responsibilities, as well as the rights and responsibilities of the health care providers. The Law introduces some new patients' rights (for example, right to second expert opinion) and new mechanisms for protection of patients' rights (Councilors for protection of patients' rights, Commissions for promotion of patients' rights). As this paper shows, the implementation of this Law is lagging remineralization potential of two toothpastes, one of which was based on Recaldent (CPP- ACP) and the other on NovaMin (Calcium-sodium-phosphosilicate). Human permanent molar teeth were subjected to three consecutive demineralization cycles. These cycles were followed by remineralization of the experimental groups by toothpastes containing Recalden and NovaMin respectively. The samples were analyzed by Scanning Electron Microscope, (SEM) and energy-dispersive Xray spectroscopy analysis (EDX). Extensive demineralization was noted in the control group (without remineralization) while the groups treated with the dentifices demonstrated various degrees of remineralization, as shown by formation of different types of deposits on the enamel surface. The EDX analysis showed increased amounts of $\mathrm{Ca}, \mathrm{P}$ Si and $\mathrm{Zn}$ in the enamel of the experimental groups, compared to the control one. Toothpastes containing Recalden and especially NovaMin have the potential to remineralize enamel, a property which might be important in finding a substitute to pit and fissure sealing. PMID: 21638965

Gershan V, Antevska-Grujoska S. Performance of mammography equipment in the Macedonian breast screening campaign 2008/2009. Radiat Prot Dosimetry. 2011 Sep;147(1-2):187-91. Epub 2011 Jul 5.

Faculty of Natural Science and Mathematics, Institute of Physics, Gazi Baba bb, 1000 Skopje, Macedonia. vesna.gershan@pmf.ukim.mk

Breast screening campaign in Macedonia started in the end of 2007 and 19 national mammography departments were included. Contrary to the European Guidelines for Quality Assurance in Mammography Screening, the quality assurance activities were not implemented before the start of the campaign, except at the University Clinic of Radiology, Skopje. The quality control tests were performed for the very first time at 13 mammography units under a licence-obtaining procedure. One of the machines was suspended from clinical and screening practice due to heavy malfunction of the generator, $X$ ray tube and automatic exposure control (AEC) system. Only 3 of the 13 mammography machines met the criteria for tube voltage (kV) accuracy. Two of the seven AEC systems were calibrated in the optimal optical density (OD) range (OD $>1.4$ ). AEC settings corresponded to the recommendations at eight units, while nine units met basic overall image quality criteria. Mean glandular dose (MGD) was higher than the recommended level of $2.5 \mathrm{mGy}$ in four departments. Mean gradient of the film $\mathrm{G}(0.25-2.0)$ was below 2.8 at four units. Only two light boxes had a luminance of $>1700 \mathrm{~cd} \mathrm{~m}(-2)$ and six rooms had an ambient light level of $<50 \mathrm{~lx}$. The findings of this work clearly suggest that the performance of the mammography equipment involved in the campaign in almost $50 \%$ do not supply basic quality criteria for a breast screening programme. PMID: 21733866

Gjorgieva D, Kadifkova-Panovska $T$, Baèeva $K$, Stafilov T. Assessment of heavy metal pollution in Republic of Macedonia using a plant assay. . Arch Environ Contam Toxicol. 2011 Feb;60(2):233-40. Epub 2010 May 28.

University "Goce Delèev", Š tip, Republic of Macedonia. darinka.gorgieva@ugd.edu.mk

Different plant organs (leaves, flowers, stems, or roots) 
from four plant species-Urtica dioica L. (Urticaceae), Robinia pseudoacacia L. (Fabaceae), Taraxacum officinale (Asteraceae), and Matricaria recutita (Asteraceae)-were evaluated as possible bioindicators of heavy-metal pollution in Republic of Macedonia. Concentrations of $\mathrm{Pb}, \mathrm{Cu}, \mathrm{Cd}, \mathrm{Mn}, \mathrm{Ni}$, and $\mathrm{Zn}$ were determined in unwashed plant parts collected from areas with different degrees of metal pollution by ICP-AES. All these elements were found to be at high levels in samples collected from an industrial area. Maximum $\mathrm{Pb}$ concentration was $174.52 \pm 1.04 \mathrm{mg} \mathrm{kg \{}{ }^{1}$ in R. pseudoacacia flowers sampled from the Veles area, where lead and zinc metallurgical activities were present. In all control samples, the $\mathrm{Cd}$ concentrations were found to be under the limit of detection (LOD <0.1 $\mathrm{mg} \mathrm{kg}\left\{{ }^{1}\right.$ ) except for R. pseudoacacia flowers and $\mathrm{T}$. officinale roots. The maximum $\mathrm{Cd}$ concentration was $7.97 \pm 0.15$ $\operatorname{mg~kg}\left\{{ }^{1}\right.$ in R. pseudoacacia flowers from the Veles area. Nickel concentrations were in the range from $1.90 \pm 0.04$ to $5.74 \pm 0.03 \mathrm{mg} \operatorname{kg}\left\{{ }^{1}\right.$. For U. dioica leaves and $\mathrm{R}$. pseudoacacia flowers sampled near a lead-smelting plant, concentrations of $465.0 \pm 0.55$ and $403.56 \pm 0.34$ mg kg\{ ${ }^{1}$ Zn were detected, respectively. In all control samples, results for $\mathrm{Zn}$ were low, ranging from $10.2 \pm$ 0.05 to $38.70 \pm 0.18 \mathrm{mg} \mathrm{kg}\left\{{ }^{1}\right.$. In this study, it was found that the flower of R. pseudoacacia was a better bioindicator of heavy-metal pollution than other plant parts. Summarizing the results, it can be concluded that T. officinale, U. dioica, and R. pseudoacacia were better metal accumulators and M. recutita was a metal avoider. PMID: 20508923

\section{Gjorgievska E, Nicholson JW. Prevention of enamel demineralization after tooth bleaching by bioactive glass incorporated into toothpaste. Aust Dent J. 2011 Jun;56(2):193-200.}

Faculty of Dental Medicine, Department of Paediatric and Preventive Dentistry, University 'Ss Cyril and Methodius' Skopje, Macedonia. elizabetag2000@yahoo.com

BACKGROUND: The aim of this study was to determine the effects of bleaching on the structure of the enamel layer of teeth and the potential of the commercial bioactive glass NovaMin ${ }^{\circledR}$ in two different toothpastes to remineralize such regions of the enamel. Three aspects were considered: the extent and nature of the alterations in the enamel after application of the bleaching agents; the extent of remineralization after application of two commercial toothpastes containing bioactive glass; and whether or not there were differences between the toothpastes in terms of their effectiveness in promoting remineralization. METHODS: Bleaching agent based on $16 \%$ carbamide peroxide was applied to the enamel surface of freshly extracted human molars for 8 minutes, once a day for 7 days. After the bleaching cycles, the enamel surface was analysed by SEM and EDX. RESULTS: The results obtained in the study lead to the conclusion that application of $16 \%$ carbamide peroxide causes distinct morphological changes to the enamel surface which vary from mild to severe. Subsequent treatment with either of the toothpastes containing the bioactive glass NovaMin $®$ resulted in the formation of a protective layer on the enamel surface, consisting of bioactive glass deposits, with only slight differences between the two brands. Application of these dentifrices also caused increases in the $\mathrm{Ca}$ and $\mathrm{P}$ content of the enamel layer, returning it to that of undamaged enamel. CONCLUSIONS: Remineralizing toothpastes should be used after bleaching, in order to repair any damage to the mineral tissue caused by these procedures. PMID: 21623812

Gucev Z, Tasic V, Saranac L, Stobbe H, Kratzsch J, Klammt J, Pfäffle R. A novel GH1 mutation in a family with isolated growth hormone deficiency type II. Horm Res Paediatr. 2012;77(3):200-4. Epub 2011 Dec 22.

Medical Faculty Skopje, Skopje, Macedonia. gucevz@gmail.com

BACKGROUND: Four distinct familial types of isolated $\mathrm{GH}$ deficiency (IGHD) have been described so far. OBJECTIVE: We report a novel nonsense GH1 mutation in a father and a son. PATIENTS: Father's height was $137.3 \mathrm{~cm}$ (-6.79 SDS); mother's height was $157.3 \mathrm{~cm}$ (-1.86 SDS). By the age of 8.25 years, his height was $104.3 \mathrm{~cm}$ (-4.82 SDS) and his weight was $18.3 \mathrm{~kg}$ (-3.35 SDS). GH stimulation tests had low peak GH value of 6.5 $\mathrm{ng} / \mathrm{ml}$ (proband) and $6.3 \mathrm{ng} / \mathrm{ml}$ (father). Other pituitary hormones and magnetic resonance imaging (MRI) of the pituitary region was normal in both patients. The proband received recombinant human $\mathrm{GH}(\mathrm{rhGH})$ treatment (30 ig/kg/day) and he grew $15.4 \mathrm{~cm}$ in 15 months. RESULTS: Sequencing of the GH1 gene revealed a novel heterozygous nonsense mutation in both the father and the son (c.199A>T), which introduces a stop codon in exon 3. CONCLUSION: We present a family with IGHD II, with severe short stature, no phenotypic characteristics of GHD and a novel nonsense 
mutation in exon 3 of the GH1 gene. As fibroblasts were unavailable, we used computer analysis and we propose a unique mechanism that combines aberrant splicing and derogated $\mathrm{GH}$ release from the pituitary with residual secretion of a bioinactive truncated $\mathrm{GH}$ peptide. PMID: 22188748

Gucev Z, Muratovska O, Laban N, Misevska L, Jancevska A, Crolla J, Tasic V. Billateral polycystic kidneys in a girl with WAGR syndrome. Indian $\mathbf{J}$ Pediatr. 2011 Oct;78(10):1290-2. Epub 2011 Jun 10.

University Children's Hospital, Medical Faculty Skopje, 50 Divizija BB, 1000 Skopje, Macedonia. gucevz@gmail.com

The WAGR contiguous gene deletion syndrome is a combination of Wilms tumor, aniridia, genito-urinary abnormalities, and mental retardation. An 8.5-year-old girl was initially investigated at the age of 18 months for congenital bilateral aniridia, cataracts, glaucoma and epicantus. The ultrasound (US) scan showed polycystic kidney disease. FISH study revealed deletion of the WT1 and PAX6 gene in the 11p13 WAGR region. Forty days after the first kidney US, the second US revealed a $3 \mathrm{~cm}$ tumor in the right kidney: a Wilms tumour, treated successfully with the Wilm's tumor protocol. The authors conclude that the identification of the deletions in the WAGR region in patients with aniridia should definitely be done. In addition, Wilms tumor can have a very rapid growth, which, per se requires frequent and careful ultrasound kidney controls. Polycystic kidneys can be part of the WAGR presentation. PMID: 21660403

Gucev Z, Slavevska N, Tasic V, Laban N, PopJordanova N, Danilovski D, Woolf J, Cole D. Congenital erythropoietic porphyria with two mutations of the uroporphyrinogen III synthase gene (Cys73Arg, Thr228Met). Indian J Hum Genet. 2011 May;17(2):104-7.

Clinical Center, Faculty of Medicine Skopje, 50 Divizija BB, 1000 Skopje, Macedonia.

Congenital erythropoietic porphyria (CEP) is an autosomal recessive inborn error of metabolism that results from the markedly deficient activity of uroporphyrinogen III synthase (UROS). We describe a 14-year-old girl with red urine since infancy, progressive blistering and scarring of the skin, and moderate hemolytic anemia. After years of skin damage, her face is mutilated; she has a bald patch on the scalp, hypertrichosis of the Domestic and peer violence in Macedonia is similar to other developed nations. It is present among adolescents and their families. A study was conducted on 664 secondary school students throughout Macedonia. The results indicated that $11.2 \%$ male and $16.54 \%$ female students often face different kinds of family violence. Peer violence of different forms is marked as "often" in $8.04 \%$ male respondents and 5.63\% female respondents. One of possibilities in preventing this negative phenomenon is the application of telemedicine. There is a growing body of evidence that the use of telemedicine offers a good tool for mental healthcare in underserved communities, and that these services are as effective as face-to-face work with adolescents. By building an effective telemedicine network in Macedonia, both victims (adolescents) and their parents could be given a chance to contact proper institutions for help with more confidence and less stress. PMID: 21882995

Gucev Z, Ristoska-Bojkovska N, Popovska-Jankovic K, Sukarova-Stefanovska E, Tasic V, PlaseskaKaranfilskaD, Efremov GD. Cystinuria AA(B): digenic inheritance with three mutations in two cystinuria genes. J Genet. 2011 Apr;90(1):157-9.

Faculty of Medicine, University Children's Hospital, Skopje 1000, Republic of Macedonia. gucevz@gmail.com

No abstract available. PMID: 21677404

Gucev ZS, Danilovski D, Tasic V, Ugrinovski J, Nastova V, Jancevska A, Krstevska-Konstantinova M, Pop-Jordanova N, Kirovski I. Childhood craniopharyngioma in Macedonia: incidence and outcome after subtotal resection and cranial irradiation. World J Pediatr. 2011 Feb;7(1):74-8. Epub 2010 Dec 30.

Medical Faculty Skopje, 50 Divizija BB, 1000 Skopje, Macedonia.gucevz@gmail.com

BACKGROUND: craniopharyngioma is a frequent tumor in children with challenging surgical, endocrine, and visual consequences. We evaluated our experience in treating craniopharyngioma and its incidence in Macedonia. METHODS: Thirteen children ( 9 male and 4 female) with craniopharyngioma (age $9.55 \pm 3.74$ years; range 2.90-15.11) who had been treated between 1989 and 2008 in Macedonia were reviewed. RESULTS: 
initial signs were vision disturbances (10 children), seizures (1), growth retardation (13), and diabetes insipidus (DI) (2). All children were subjected to subtotal surgical removal. Cranial irradiation was performed in 12 of the 13 children, and intracystic bleomycin was given to one child. The patients were followed up for 6229 months (mean \pm SD: $107.00 \pm 74.04$ months). All children had multiple pituitary deficiencies after surgical removal of the tumor. Body mass index increased from $16.93 \pm 6.34$ standard deviation scores (SDS) at diagnosis to $26.33 \pm 5.91$ SDS $(P>0.005)$ at the last follow-up. DI was permanent in 9 of the 13 children, and multiple pituitary deficiencies were seen in all children. Treatment with growth hormone resulted in normalization of adult height from $-1.27 \pm 1.52$ SDS at the start of the treatment to $-0.13 \pm 1.39$ SDS at the last followup. The final height was not significantly lower than the genetic target height ( $P>0.005)$. The permanent deficit was visual impairment: blindness in one or both eyes in 4 children, bitemporal hemianopsia in 4, and other defects in 2 . Recurrence of the disease was ruled out in one child after 31 months. No mortality was observed in the observation period of $104.92 \pm 76.11$ months. CONCLUSIONS: the overall incidence of craniopharyngioma in the period of 19892008 in Macedonia was 1.43 per 1000000 personyears. Subtotal resection and systematic irradiation showed good life quality of survivors. PMID: 21191780

Gulaboski R, Mihajlov L. Catalytic mechanism in successive two-step protein-film voltammetrytheoretical study in square-wave voltammetry. Biophys Chem. 2011 Apr;155(1):1-9. Epub 2011 Feb 23.

Faculty of Agriculture, Goce Delèev University, Š tip, Macedonia.rubin.gulaboski@ugd.edu.mk

Protein-film voltammetry is established as an effective tool that provides insight to the redox features of various lipophilic proteins by using a simple methodology. Although the protein-film experimental set up is relatively simple, the redox mechanisms of many proteins are quite complicated, and very often they cannot be resolved without having support from adequate mathematical models. In this work we continue our contribution to modeling relevant redox mechanisms in protein-film voltammetry. We present results from the theoretical simulations of catalytic mechanism at the two-step successive surface redox reaction under conditions of square-wave voltammetry. This mechanism is assigned as a surface EEC', and it can be presented by the following simplified scheme: $A($ ads)+ne- $\leftrightarrow B$ (ads)+ne$\leftrightarrow \mathrm{C}($ ads)+Substrate '! $\mathrm{k}$ (cat)B(ads). Our attention is focused on several phenomena of this complex proteinfilm mechanism, while we give set of qualitative criteria to distinguish this mechanism from similar ones studied under voltammetric conditions. Moreover, we also provide hints to use methodologies for the determination of thermodynamic and kinetic parameters relevant to the protein-film EEC' mechanism. The considered proteinfilm EEC' mechanism is applicable to all lipophilic redox proteins that undergo electrochemical transformations in more than one successive electron steps. Such examples exist by proteins containing quinone moiety and some polyvalent ions of transition metals as redox active sites. PMID: 21349631

Hadzi-Petrushev N, Jankulovski N, Hristov K, Mladenov M. L-2-oxothiazolidine-4-carboxylate influence on age- and heat exposure-dependent redox changes in rat's blood plasma. J Physiol Sci. 2011 Sep;61(5):437-42. Epub 2011 Jul 24.

Faculty of Natural Sciences and Mathematics, Institute of Biology, Ss, Cyril and Methodius University, Skopje 1000, Macedonia.

In the present study, we investigated both the age- and heat exposure-related redox changes of blood plasma by analyzing GSH, thiol status and carbonyl groups. Our results clearly indicated that the plasma redox balance shifted toward oxidation during both aging and acute heat exposure. To further confirm this age- and heat exposure-related redox shift, we quantified the changes in thiol content. The total thiol level was found to be significantly decreased in the aged group. A similar pattern can be explained by low levels of serum GSH in old rats compared to young rats. The significance of the present study are the data showing increased oxidative stress in plasma during aging, attributed to a decrease in major antioxidant components in serum. OTC treatment, in relation to $\mathrm{C}=\mathrm{O}$ regarded as a marker of oxidative damage was probably much more effective in increasing of GSH synthesis than in prevention of protein oxidation. PMID: 21786149

Haxhihamza K, Doarn CR, Marija R, Dimitrinka JP, Rozalinda I, Izabela F, Viktor I, Lidija S. Domestic and peer violence in secondary school among adolescents: can telemedicine help? Telemed J E Health. 2011 Nov;17(9):700-4. Epub 2011 Sep 1. 
Clinic of Psychiatry-Medical Faculty, University St. Cyril and Methodius, Skopje, Macedonia. kadrihadzihamza@gmail.com

Domestic and peer violence in Macedonia is similar to other developed nations. It is present among adolescents and their families. A study was conducted on 664 secondary school students throughout Macedonia. The results indicated that $11.2 \%$ male and $16.54 \%$ female students often face different kinds of family violence. Peer violence of different forms is marked as "often" in $8.04 \%$ male respondents and 5.63\% female respondents. One of possibilities in preventing this negative phenomenon is the application of telemedicine. There is a growing body of evidence that the use of telemedicine offers a good tool for mental healthcare in underserved communities, and that these services are as effective as face-to-face work with adolescents. By building an effective telemedicine network in Macedonia, both victims (adolescents) and their parents could be given a chance to contact proper institutions for help with more confidence and less stress. PMID: 21882995

Hristov N, Atanasov Z, Zafirovski G, Mitrev Z. Intramuscular cavernous hemangioma in the left soleus muscle: successful surgical treatment. Interact Cardiovasc Thorac Surg. 2011 Nov;13(5):521-2. Epub 2011 Aug 18.

Department of Surgery, Filip Vtori Special Hospital for Surgery, Skopje, Macedonia. hristov@cardiosurgery.com.mk

We describe here the case of a 16-year-old boy successfully treated at our hospital for intramuscular cavernous hemangioma in the left soleus muscle. The patient was diagnosed using magnetic resonance imaging and open biopsy after attempted/failed surgery at another institution. We performed lower leg phlebography in order to identify all the feeding and draining veins of the cavernous hemangioma. Our surgical approach of ligation of the feeding and draining veins of the intramuscular cavernous hemangioma with subsequent thrombosis of the hemangioma proved successful, resulting in cure with no operative or postoperative complications, a minimal hospital stay and a good functional and cosmetic outcome. PMID: 21852266

Hristovski R, Davids K, Araujo D, Passos P. Constraints-induced emergence of functional novelty in complex neurobiological systems: a basis for creativity in sport. Nonlinear Dynamics Psychol Life Sci. 2011 Apr;15(2):175-206.

Sts. Cyril and Methodius University, Macedonia. robert_hristovski@yahoo.com

In this paper we present a model of creativity captured as exploration and production of novel and functionally efficient behaviors, based on the statistical mechanics of disordered systems. In support of the modelling, we highlight examples of creative behaviors from our research in sports like boxing and rugby union. Our experimental results show how manipulation of practice task constraints changes the exploratory breadth of the hierarchically soft-assembled action landscape. Because of action metastability and differing task constraints, the specificity of each assembled movement configuration is unique. Empirically, a movement pattern's degree of novelty may be assessed by the value of the order parameter describing action. We show that creative and adaptive movement behavior may be induced by at least two types of interven-tions, based on relaxing task constraints which we term direct and indirect. Direct relaxing is typically a function of changing task constraints so that the number of affordances that can satisfy goal constraints increases. Indirect relaxing of constraints occurs when a habitual action is suppressed by, for example, stringent instructional constraints during sports training. That suppression simultaneously relaxes other correlated constraints that enable larger exploratory capacity and new affordances to emerge for the athlete or team. PMID: 21382260

Ivanovski N, Masin J, Kolevski P, Stojceva-Taneva O, Popov Z. Use of elderly living kidney donors: twenty years' experience in the Balkans. Transplant Proc. 2011 Nov;43(9):3415-7.

University Clinic of Nephrology, Medical Faculty, Skopje, Republic of Macedonia.nivanovski@yahoo.com

The Balkan region has dramatically changed during the last 20 years. Despite transplantation efforts, dialysis remains the usual way to treat end stage renal diseases. Living donor renal transplantation is still the predominant transplant activity. Seeking to solve the problem, we decided to accept expanded criteria living donors, including elderly, marginal, unrelated, and ABOincompatible individuals. Herein we have presented our 20 years' experience with 230 living donor renal transplantations using elderly individuals, including 90 
older than 65 years (mean age $68 \pm 4.5$; range $=65-86$; ED group). The predominantly haploidentical recipients had a mean age of $45 \pm 6$ years (range $=18-66$ ) Sequential immunosuppressive protocols were used in all cases including induction with anti-thymocyte-globulin or interleukin-2 receptor antagonists. We analyzed the 5-year Kaplan-Meier graft survival rate, rejection episodes, delayed graft function, and renal function for comparison with these outcomes of 110 kidneys from younger donors ( mean age $=53.4$ years; range $=25-62$; YD group) and haploidethical recipients (mean age $=$ 32.2 , range $=16-42$ ), performed within the same period. The 3- and 5-year cumulative graft survival rates in the ED group were $81 \%$ and $72 \%$ compared with $85 \%$ and $81 \%$ in the YD group respectively ( $P>.9 ; N S)$. The incidences of acute rejection episodes were also comparable for both groups (19\% and $17 \%$, respectively). Delayed graft function occurred in 15\% of the ED group but only $8 \%$ of the YD group. The serum creatinine value at the end of 60 months' follow-up was $146.04 \mathrm{ì} \mathrm{mol} / \mathrm{L}$ in the ED group versus $123.38 \mathrm{i} \mathrm{mol} / \mathrm{L}$ in the $\mathrm{YD}$ group $(\mathrm{P}<$ $.001)$. There were no major surgical complications in either group. We recommend the use of elderly living donors as a valuable source of kidneys, especially in countries wherein deceased donor transplantation is not yet established. PMID: 22099810

Ivanovski N, Masin J, Rambabova-Busljetic I, Pusevski V, Dohcev S, Ivanovski O, Popov Z. The outcome of commercial kidney transplant tourism in Pakistan. Clin Transplant. 2011 Jan-Feb;25(1):1713.

University Clinic of Nephrology, Medical Faculty, University Ss Cyril and Methodius, Skopje, Macedonia. nivanovski@yahoo.com

Comment in Clin Transplant. 2011 May;25(3):E223-4.

The lack of cadaver organs for transplantation motivates some Balkan patients to go to developing countries to buy a kidney. We have followed 36 patients who received kidney transplants in Lahore and Rawalpindi, Pakistan. The patients had not been cleared for transplantation with a standard pre-transplant work-up: $80 \%$ were hepatitis-C virus (HCV) or HBsAg positive. During followup, seven patients died. Sixteen patients experienced wound infections with post-operative hernias, and three patients developed peri-renal hematomas. Six abscesses and four lymphoceles occurred, and four urinary fistulas were surgically treated. Nephrectomy was performed in three patients because of renal artery thrombosis. Nine patients developed active hepatitis $\mathrm{C}$, and four patients manifested cytomegalovirus disease. Three patients developed steroid diabetes, and three patients experienced acute myocardial infarction. Nine patients had one or more rejection episodes. Urinary tract infection with Pseudomonas or Escherichia occurred frequently. The one-yr patient and graft survival rates were $80 \%$ and $68 \%$, respectively. Paid unregulated renal transplantation is not recommended for both ethical reasons and because of an association with excessive morbidity and mortality. PMID: 20626425

Jakovski Z, Nikolova K, Jankova-Ajanovska R, Janeska B, Pojskic N, Marjanovic D. Allele frequencies of the new European Standard Set (ESS) loci plus SE33 locus in a population from the Republic of Macedonia. Forensic Sci Int Genet. 2012 May;6(3):e90-2. Epub 2011 Jul 28.

No abstract available.

PMID: 21802383

Jakovski Z, Jankova R, Nikolova K, Spasevska L, Jovanovic R, Janeska B. Forensic DNA expertise of incest in early period of pregnancy. J Forensic Leg Med. 2011 Jan;18(1):34-7. Epub 2010 Dec 13.

Institute of Forensic Medicine, Criminology and Medical Deontology, School of Medicine, University Ss. Cyril and Methodius, Skopje, Macedonia. zlatedr@yahoo.com

Proving incest from tissue obtained by abortion early in pregnancy can be a challenge. Problems include the small quantity of embryonic tissue in the products of conception, and the mixing of DNA from mother and embryo. In many cases, this amorphous material cannot be grossly segregated into maternal and fetal components. Thus, morphological discrimination requires microscopy to select relevant tissue particles from which DNA can be typed. This combination of methods is reliable and efficient. In this article, we present two cases of incest discovered by examination of products of conception. Copyright Â@ 2010 Elsevier Ltd and Faculty of Forensic and Legal Medicine. PMID: 21216379

Jakovski Z, Nikolova K, Jankova-Ajanovska R, Marjanovic D, Pojskic N, Janeska B. Genetic data for $17 \mathrm{Y}$-chromosomal STR loci in Macedonians in the Republic of Macedonia. Forensic Sci Int Genet. 2011 


\section{Aug;5(4):e108-11. Epub 2011 May 5.}

Institute of Forensic Medicine and Criminology, School of Medicine, University Ss. Cyril and Methodious, Skopje, Macedonia.zlatedr@yahoo.com

The population data were obtained for the $16 \mathrm{Y}$ chromosomal STR loci included in the AmpFistr(®)Yfiler ${ }^{\mathrm{TM}}$ PCR Amplification Kit (DYS456, DYS389I, DYS390, DYS389II, DYS458, DYS19, DYS385 a/b, DYS393, DYS391, DYS439, DYS635, DYS392, Y-GATA H4, DYS437, DYS438, DYS448) in a sample of 262 unrelated men from the Republic of Macedonia. PMID: 21549657

Jasovic-Siveska E, Jasovic V. Demographic characteristics in preeclamptic women in Macedonia. Rev Med Chil. 2011 Jun;139(6):748-54. Epub 2011 Sep 14.

Policlinic Neuromedica, Bitola, Republic of Macedonia. medihelp@t-home.mk

BACKGROUND: Worldwide, pre-eclampsia and eclampsia contribute to the death of a pregnant woman every three minutes. AIM: To determine the demographic risk factors and values of blood pressure to predict preeclampsia. MATERIAL AND METHODS: Demographic and clinical features of 300 normotensive pregnant women aged $28 \pm 5$ years and 100 preeclamptic women aged $28 \pm 6$ years, were assessed. Women with multiple pregnancies were excluded from the study. RESULTS: Women with less educational attainment had a higher risk of mild and severe preeclampsia. Weight gain during pregnancy in control and pre eclamptic women were $14 \pm 3$ and $20 \pm 5 \mathrm{~kg}$, respectively $(p<0.01)$. Women with severe preeclampsia had high significantly shorter gestations then the other two patient groups $(p<$ 0.01). Compared to normotensive women, at 6 to 12 weeks of gestation, pre eclamptic women had higher systolic (102 \pm 7 and $113 \pm 9 \mathrm{mmHg}$ respectively), diastolic (64 \pm 5 and $74 \pm 10 \mathrm{mmHg}$ respectively) and mean arterial pressure $(77 \pm 5$ and $87 \pm 8.01 \mathrm{mmHg}$ respectively). CONCLUSIONS: Women with basic education or illiterate have a higher risk of developing preeclampsia. During the first or second trimester of pregnancy, mean arterial pressure is the best predictor for preeclampsia. PMID: 22051755

Jasovic-Siveska E, Jasovic V, Stoilova S. Previous pregnancy history, parity, maternal age and risk of pregnancy induced hypertension. Bratisl Lek Listy. 2011;112(4):188-91.

School of Nursing, Dept. of Gynecology and Obstetrics, University St. Kliment Ohridski, Bitola, Macedonia. valentino.siveski@t-home.mk

OBJECTIVE: The influence of antepartal, intrapartal and early neonatal risk factors, are very important during the pregnancy and the pregnancy outcome, also for the early neonatal period and the forthcoming children development. Our aim is to detect the risks groups of pregnant women that later develop Pregnancy Induced Hypertension (PIH) and risk factors that precede its appearance. PATIENTS AND METHODS: We examined 67 preeclamptic and 129 normotensive pregnancies. In research are included only single pregnancies and the following parameters: maternal age, parity and previous pregnancy history. RESULTS: Average age is 25.73+/5.77 years. After all, the largest number of primipara with preeclampsia is in category from 20 years $(p<0.01)$. Considering the multipara we noticed that preeclampsia is most commonly developed in age between 31-35 years $(p<0.01)$. Biggest number of pregnancies in normotensive group had previous normal pregnancies (59.15\%), while in hypertensive group only $30.77 \%$ patients had normal pregnancies $(p<0.05)$. CONCLUSIONS: PIH is most frequently appearing in young primiparas and adult multiparas. Pregnancies with $\mathrm{PIH}$, really often there were negative ending of previous pregnancies (Tab. 5, Ref. 20). Full Text in free PDF www.bmj.sk. PMID: 21585125

\section{Jasovic-Siveska E, Jasovic V. Prediction of mild and severe preeclampsia with blood pressure measurements in first and second trimester of pregnancy. Ginekol Pol. 2011 Nov;82(11):845-50.}

PZU Medika, Department of Gynecology and Obstetrics, Bitola FYROM, Bitola, Macedonia. medihelp@t-home.mk

OBJECTIVES: The study was designed to determine the accuracy of using systolic (SBP) and diastolic blood pressure (DBP), mean arterial pressure (MAP), and increase of blood pressure (BP) to predict Preeclampsia (PE). MATERIALS AND METHODS: We examined 300 normotensive and $100 \mathrm{PE}$ pregnancies divided in two subgroups: mild $(n=67)$ and severe $(n=33)$ PE. The patients had a BP check in first and second trimester (SBFP DBP and MAP). RESULTS: We found out significant difference between the groups, but what is 
more important is that the difference in $\mathrm{BP}$ values (especially diastolic and MAP) existed before the pathological increase of the BP above the normal values. This was happening most often after $31 \mathrm{wg}$ (at 92.5\%) and less often after $26 \mathrm{wg}$ (at 7.5\%) at the pregnancies with mild PE while at the pregnancies with severe PE, $18,2 \%$ had increased tension after $21 \mathrm{wg} ; 24 \%$ in the period of $26-30 \mathrm{wg}$ and $57.58 \%$ after $31 \mathrm{wg}$. CONCLUSION: Based on the results we could conclude that when BP is measured in the first or second trimester of pregnancy the MAP is a better predictor for PE than SBP and DBPR. PMID: 22384618

Jordanova M, Rocha MJ, Rebok K, RochaE. Changes in the amount of kidney pigmented macrophage aggregates throughout the breeding cycle of female Ohrid trout, Salmo letnica Kar. (Teleostei, Salmonidae). Microsc Res Tech. 2012 Feb;75(2):176-81. Epub 2011 Jul 14.

Laboratory of Histology and Embryology, Institute of Biology, Faculty of Natural Sciences and Mathematics, Republic of Macedonia.majaj@pmf.ukim.mk

Changes in fish macrophages (Macs) are useful indicators of environmental pressures, but responses due to chemical and nonchemical stresses may be confounded by natural sources of variability. These may include sex and gonadal stage. In this study, we start addressing the following question: is the seasonally dependent ovary stage a factor to consider when using kidney Macs as biomarkers? To tackle this problem, the relative amount of pigmented Macs in kidney (head, trunk, and tail portions) was stereologically estimated in Ohrid trout, and related with the breeding status. The amount of Macs significantly increased from pre vitellogenesis to late vitellogenesis and showed a decreasing trend then after, with lower values noted after spawning in the head $(1.9 \%$ versus $7.5 \%$ versus $2.0 \%)$, trunk (1.8\% versus $7.5 \%$ versus $2.5 \%)$, and tail (2.5\% versus $6.7 \%$ versus $2.9 \%)$ kidney. The decrease seen at spawning was significant in head and trunk kidney, and at post spawning it was significant for all kidney portions. The amounts of Macs were positively correlated with the ovary relative weights and plasma estradiol levels. We proved for the first time that fish kidney pigmented Macs can vary in amount during the breeding cycle. Our data, combined with literature, strongly support that the sex-steroid profile and kidney status-seasonal remodeling both influence the Macs pool; likely not only in female trout. So, while increases in Macs may warn of ecosystem problems, we show that using kidney Macs for biomonitoring should also take into account seasonally, particularly that related with ovary maturation. PMID: 21761499

Kajdzanoska M, Petreska J, Stefova M. Comparison of different extraction solvent mixtures for characterization of phenolic compounds in strawberries. J Agric Food Chem. 2011 May 25;59(10):5272-8. Epub 2011 Apr 22.

Institute of Chemistry, Faculty of Natural Sciences and Mathematics, Sts Cyril and Methodius University, Skopje, Republic of Macedonia.

Eight different solvent mixtures containing acetone or methanol pure or combined with an acid (acetic, formic, hydrochloric) were tested for their efficiency for extraction of phenolic compounds from strawberries belonging to five groups of polyphenols: anthocyanins, flavonols, flavan-3-ols, hydroxycinnamic acid derivatives and conjugated forms of ellagic acid. Twenty-eight compounds from these five groups have been detected and quantified using HPLC-DAD-ESI-MS(n). The yield of each phenolic compound and group was evaluated with regard to the extraction solvent composition. Acetone containing extraction mixtures were superior to the ones containing methanol for extraction yield of total phenolic compounds, which was especially pronounced for the groups of flavan-3-ols and conjugated forms of ellagic acid. The mixture acetone/acetic acid (99:1, v/v) gave the best results for the qualitative and quantitative assay of the polyphenols present in strawberries since all 28 compounds were detected only in these extracts in PMID: 21435208

\section{Kedev S. Transradial and transulnar access for percutaneous coronary interventions. Turk Kardiyol Dern Ars. 2011 Jun;39(4):332-40.}

University Clinic of Cardiology, Medical Faculty Skopje, Macedonia.skedev@mt.net.mk

Periprocedural bleeding and vascular complications after percutaneous coronary intervention $(\mathrm{PCl})$ are associated with worse clinical outcomes and increased short- and long-term mortality. Vascular access-related bleeding accounts for more than $80 \%$ of all major bleeding events in $\mathrm{PCl}$ performed by the transfemoral approach. Transradial approach (TRA), on the other hand, virtually eliminates access site bleeding and vascular 
complications. Although clinical trials have mostly evaluated different pharmacological strategies for reducing bleeding risk, adoption of a radial rather than a femoral access may allow greater reductions in bleeding complications than pharmacological strategies alone. High-risk patients such as those with acute coronary syndrome and ST-segment elevation myocardial infarction, women, obese patients, and elderly subjects who are at increased risk for vascular complications and bleeding might particularly benefit from the radial approach. Besides increased patient safety, the TRA is associated with improved patient satisfaction, reduced cost, and length of hospital stay, thus allowing outpatient performance of uncomplicated PCI. PMID: 21646838

Kendrovski V, Karadzovski Z, Spasenovska M. Ambient maximum temperature as a function of Salmonella food poisoning cases in the Republic of Macedonia. N Am J Med Sci. 2011 Jun;3(6):264-7.

Department of Environmental Health, Institute for Public Health of Republic of Macedonia, Skopje, Republic of Macedonia.

BACKGROUND: Higher temperatures have been associated with higher salmonellosis notifications worldwide. AIMS: The objective of this paper is to assess the seasonal pattern of Salmonella cases among humans. MATERIAL AND METHODS: The relationship between ambient maximum temperature and reports of confirmed cases of Salmonella in the Republic of Macedonia and Skopje during the summer months (i.e. June, July, August and September) beginning in 1998 through 2008 was investigated. The monthly number of reported Salmonella cases and ambient maximum temperatures for Skopje were related to the national number of cases and temperatures recorded during the same timeframe using regression statistical analyses. The Poisson regression model was adapted for the analysis of the data. RESULTS: While a decreasing tendency was registered at the national level, the analysis for Skopje showed an increasing tendency for registration of new salmonella cases. Reported incidents of salmonellosis, were positively associated $(P<0.05)$ with temperature during the summer months. By increasing of the maximum monthly mean temperature of $1^{\circ} \mathrm{C}$ in Skopje, the salmonellosis incidence increased by $5.2 \%$ per month. CONCLUSIONS: THE INCIDENCE OF SALMONELLA CASES IN THE MACEDONIAN POPULATION VARIES SEASONALLY: the highest values of the Seasonal Index for Salmonella cases were registered in the summer months, i.e. June, July, August and September. PMCID: PMC3336917. PMID: 22540096

Kocova M, Zdraveska N, Sukarova-Angelovska E. Unique concurrent appearance of two rare conditions in a young girl: central precocious puberty due to hypothalamic hamartoma and uncommon type of diabetes. J Pediatr Endocrinol Metab. 2011;24(910):815-8.

Department of Endocrinology and Genetics, University Children's Hospital, Skopje, Macedonia. mirjanakocova@yahoo.com

Hypothalamic hamartomas $(\mathrm{HH})$ are rare congenital nonneoplastic lesions of the tuber cinereum, which usually present as precocious puberty of central origin in young girls and respond well to treatment with long acting gonadotropin releasing hormone $(\mathrm{GnRH})$ analogs. No association of this condition with diabetes mellitus of any form has been reported so far. On the other hand, diabetes mellitus in children and adolescents, when it is not autoimmune type 1 diabetes, is difficult to classify. We present a girl with early onset of central precocious puberty at the age of 8 months, due to hypothalamic hamartoma. Treatment with depot of a GnRH analog for a period of 9 years and 8 months was successful, and her puberty continued 6 months after the discontinuation of triptorelin. At the age of 9 years 6 months, the girl presented with diabetes. She was negative for islet, GAD and IA2 antibodies and her insulinemia and Cpeptide remained within normal limits during the 2 years of follow-up. Her metabolic control is excellent with a combination of metformin and a low-dose of mixed insulin. To our knowledge, this is the first description of the simultaneous appearance of these two endocrinological conditions. PMID: 22145483

Kostovski A, Zdraveska N. Coagulopathy as initial manifestation of concomitant celiac disease and cystic fibrosis: a case report. J Med Case Rep. 2011 Mar 24;5:116.

University Children's Hospital, Department for Gastroenterology and Hepatology, Skopje, Former Yugoslav Republic of Macedonia. acokos@gmail.com.

INTRODUCTION: Celiac disease and cystic fibrosis have many common manifestations, such as malabsorption, steatorrhea and growth failure, and were 
for many years recognized as one clinical entity. Since their recognition as two separate diseases, their coexistence in a patient has been described sporadically; around 20 cases have been described in the literature. Taking into consideration the incidences of the two diseases, the chance of them occurring together is one in $2,000,000$ in the general population. CASE PRESENTATION: We describe the case of a five-yearold boy of Turkish ethnicity with both celiac disease and cystic fibrosis, who presented initially with a skin hemorrhage. The diagnosis of celiac disease was made with a positive serum anti-tissue transglutaminase antibody test and the presence of HLA-DQ2 heterodimer, and confirmed on histology with small intestinal villous atrophy. A positive sweat test confirmed the diagnosis of associated cystic fibrosis. To the best of our knowledge there has been no previous report of this rare presentation of associated celiac disease and cystic fibrosis. CONCLUSION: The clinical significance of this case is the consideration of malabsorption with both celiac disease and cystic fibrosis in patients who present with unexplained coagulopathy. PMCID: PMC3070667 PMID: 21435208

Krstevska S, Genadieva-Stavric S, Pivkova A, Stojanovski Z, Georgievski B, Balkanov T. Acute graft versus host disease in hematopoietic stem cell alotransplant recipients. Med Arh. 2011;65(5):260-4.

Hematology Clinic, Clinical Center of University of Skopje, Republic of Macedonia.

INTRODUCTION: The transplantation of hematopoietic stem cells (HSCT) is a therapeutic intervention where the hematopoietic stem cells and the cells originating from them are being removed and replaced by the normal stem cells of donor or the patient him/her-self. HSCT today represent standardized biological manipulation for treating malignant, genetic and autoimmune diseases. The application of allogeneic hematopoietic stem cell transplantation (HSCT) is limited by life-threatening complications such as severe or acute graft-versus-host disease (GVHD). Despite intensive prophylaxis with immunosuppressive agents, the incidence of GVHD occurs in $9-50 \%$ of patients undergoing transplant with an identical HLA sibling matched donor and $75 \%$ of patients undergoing unrelated HLA donors. AIM OF STUDY: To evaluate our experiences in GVHD prophylaxis and treatment after alloHSCT, GVHD incidence and prognostic factors and administration of new immunosuppressive regiments.
Can we recognize clinical parameters which are associated with occurrence and severity of graftversus-host disease? PATIENTS AND METHODS: Starting from September 2000 till September 2010, 63 patients (36 males and 27 females) at the age of 16-56 (median range 33 years) with hematological malignancies were treated with alloHSCT on Department of Hematology, Clinical Centre, Skopje. In 10 patients bone marrow was used as source of stem cells and in 53 patients stem cells were obtained from peripheral blood. From the group of 63 patients, 26 patients had active disease at the time of transplantation. GVHD prophylaxis was accomplished with combination of cyclosporine and methotrexate (Seattle regimen) or more intensive immunosuppression regiments. RESULTS: GVHD was noticed in 30 patients (47.6\%) and in 33 patients (52.4\%) a manifestation of GVHD was noticed. Acute GVHD was noticed in 24 patients (38\%) and chronic GVHD in 20 patients $(31.7 \%)$ The remaining 32 patients (45\%) achieved complete clinical and hematological remission. Lethal outcome was confirmed in $31(49 \%)$ patients (9 from chrGVHD, 6 from acute GVHD, 16 from disease relapse). CONCLUSION: The incidence of acute GVHD in our study was 38\% and 31\% for chronic GVHD. The most common GVHD reaction was registered in female donors and male recipients, with higher GVHD incidence in elderly patients. In all patients stem cells were obtained from peripheral blood. Active disease, sex, source of hematopoietic cells, age and conditional regiments are the most significant predictive factors with the high incidence of GVHD. PMID: 22073847

Ljubic A, Trajkovski V, Stankovic B. Strabismus, refractive errors and nystagmus in children and young adults with Down syndrome. Ophthalmic Genet. 2011 Nov;32(4):204-11. Epub 2011 Jul 5.

Private polyclinic Medika plus, Skopje, Macedonia. antonelalubik@yahoo.com

PURPOSE: The aims of the present population-based, cross-sectional study were to examine the frequency and type of strabismus, refractive errors and nystagmus in children and young adults with Down syndrome (DS) in Macedonia and Croatia. METHODS: A total of 170 unselected children and young adults with DS aged 1-34 years were examined for ocular findings. The ocular examination included: a visual acuity assessment, cycloplegic refraction, ocular alignment and ocular motility. RESULTS: Strabismus was found in 45 of 170 children (26.5\%), and esodeviation was the most common 
type. Nine (20\%) had exodeviation and 4 (8.9\%) vertical deviation. In 27 of 32 esotropic patients, the strabismus was regarded as acquired esodeviations. The frequency of strabismus was lowest in the high-grade hyperopia group (5\%). Concerning esodeviations, fewer cases (3\%) were in the high-grade hyperopia group. Most of the cases with esodeviations were in correlation with low-grade hyperopia (31\%), myopia (28\%) and emetropia (16\%). Hyperopia was the most common refractive error and high myopia increased in prevalence in the over 20 age group. Astigmatism was present in $72.4 \%$ of patients. Nystagmus was observed in 18 patients. Ten of 18 patients with nystagmus were associated with the presence of strabismus (9 esodeviations, 1 exotropia). CONCLUSION: In our study, the high prevalence of strabismus can not be attributed to the presence of hyperopia. Our data show no association between refraction and strabismus in children with DS. Oblique astigmatism has been found to be the most common type of astigmatism in our study group. PMID: 21728809

Ljubic A, Trajkovski V. Refractive errors in children and young adults with Down's syndrome. Acta Ophthalmol. 2011 Jun;89(4):324-7.

Medika Plus (Private Polyclinic), Skopje, Macedonia. antonelalubik@yahoo.com

Erratum in Acta Ophthalmol. 2011 Aug;89(5):500. Antonela, Ljubic [corrected to Ljubic, Antonela]; Vladimir, Trajkovski [corrected to Trajkovski, Vladimir].

PURPOSE: Down's syndrome (DS) is the most common chromosomal anomaly. Numerous ophthalmic features have been reported. The aim of our study was to investigate the incidence of refractive errors in children and young adults with DS in Macedonia. METHODS: Fifty-six children and young adults with DS, aged 2-28 years, from Macedonia, underwent slit-lamp examination, ocular motility and refraction. RESULTS: The overall incidence of refractive errors in the Macedonian children and young adults with DS was $96.4 \%$. A total of $17.8 \%$ of the subjects had myopia, $23.2 \%$ had hypermetropia and $55.3 \%$ had astigmatism. Strabismus was seen in 13 $(23.2 \%)$ of the subjects (nine had esotropia, three had exotropia, one had hypertropia). CONCLUSIONS: The incidence of refractive errors in Macedonian children and young adults with DS was similar to that in Asian children. Compared with White (Caucasian) and Asian children with DS, Macedonian children and young adults exhibited lower incidences of hypermetropia and myopia, and a higher incidence of astigmatism, in which oblique astigmatism represented the predominant type. PMID: 19843014

Lozanovski VJ, Ristoska-Bojkovska N, Korneti P, Gucev Z, Tasic V. OCRL1 mutation in a boy with Dent disease, mild mental retardation, but without cataracts. World J Pediatr. 2011 Aug;7(3):280-3. Epub 2011 Aug 7.

Medical School Skopje, University Children's Hospital, Skopje, Macedonia.v.lozanovski@yahoo.com

BACKGROUND: Oculocerebrorenal (Lowe) syndrome is an X-linked multisystem disease characterized by renal proximal tubulopathy, mental retardation, and congenital cataracts. We present a 19-year-old boy who was found to have low molecular weight proteinuria, hypercalciuria, mild generalized hyperaminoaciduria and intermittent microscopic hematuria at the age of 3 . METHODS: Standard clinical and biochemical examinations and mutational analysis of the CLNC5 and OCRL1 gene were performed for the patient. RESULTS: The patient fulfilled diagnostic criteria for Dent disease, but lacked mutation in CLCN5. Sequencing of candidate genes revealed a mutation in his OCRL1 gene, which encodes for enzyme PIP2 5-phosphatase. The enzyme was not detected by western blot analysis, and decreased activity of the enzyme PIP2 5-phosphatase was observed in cultured skin fibroblasts. The boy had only mild mental retardation, mildly elevated muscle enzymes, but no neurological deficit or congenital cataracts, which are typical for Lowe syndrome. CONCLUSIONS: Children with Dent phenotype who lack CLCN5 mutation should be tested for OCRL1 mutation. OCRL1 mutations may present with mild clinical features and are not necessarily associated with congenital cataracts. PMID: 21822997

\section{Madjunkova S, Volk M, Peterlin B, Plaseska- Karanfilska D. Detection of thrombophilic mutations related to spontaneous abortions by a multiplex SNaPshot method. Test Mol Biomarkers. 2012 Apr;16(4):259-64. Epub 2011 Oct 24.}

Research Center for Genetic Engineering and Biotechnology GeorgiD. Efremov, Macedonian Academy of Sciences and Arts, Skopje, Republic of Macedonia.

Spontaneous abortion is a significant clinical problem of different etiologies. Certain thrombophilia gene mutations have been associated with an increased risk of spontaneous abortion. Also, mutations in folate-related 
genes can lead to abnormal chromosomal segregation during meiosis which is the most common cause of spontaneous abortion. We have developed a multiplex single-base extension reaction assay that allows simultaneous analysis of 10 different mutations in thrombophilia- and folate-related genes (Factor $\mathrm{V}$ Leiden G1691A, Factor V H1299R, Factor II G20210A, Factor XIII V34L, PAI-I -675 4G/5G, FGB -455G/A, MTHFR C677T, MTHFR A1298C, MTR A2756G, and MTRR A66G). Using this method we have studied 232 women who had a spontaneous abortion and 209 of their male partners. Prevalence of Factor II G20210A and Factor V H1299R mutations was significantly higher in the women than in their male partners $(2.4 \%$ and $0.7 \%$, respectively $[p=0.0499]$ for the Factor II mutation and $9.3 \%$ and $5.7 \%$, respectively [ $\mathrm{p}=0.0485]$ for the Factor $\mathrm{V}$ mutation). The prevalence of MTHFR C677T, MTHFR A1298C, MTR A2756G, and MTRR A66G mutations did not differ between the studied groups. In conclusion, we have developed a rapid, simple, reliable, and inexpensive multiplex SNaPshot method for determination of 10 thrombophilic mutations that may result in spontaneous abortions. PMCID: PMC3326265. PMID: 22023244

Minov J, Karadzinska-Bislimovska J, Vasilevska K, Risteska-Kuc S, Stoleski S, Mijakoski D. Exerciseinduced bronchoconstriction and exercise-induced respiratory symptoms in nurses. . J Allergy (Cairo). 2011;2011:267542. Epub 2011 May 11.

Department of Cardiorespiratory Functional Diagnostics, Institute for Occupational Health of R. Macedonia-WHO Collaborating Center and GA2LEN Collaborating Center, II Makedonska Brigada 43, 1000 Skopje, Macedonia.

In order to assess prevalence and characteristics of exercise-induced respiratory symptoms (EIRSs) and exercise-induced bronchoconstriction (EIB) in health care workers, we performed a cross-sectional study including 48 female nurses from primary care settings and an equal number of female office workers studied as a control group. The evaluation of examined groups included completion of a questionnaire, skin prick tests to common inhalant allergens, spirometry, and exercise and histamine challenge. We found a similar prevalence of EIRSs and EIB in both groups. EIB was closely related to asthma, atopy, family history of asthma, and positive histamine challenge in either group, while the association between EIB and daily smoking in nurses was of borderline statistical significance. Bronchial reaction to exercise was significantly higher in nurses than in controls with EIB. With the exception of exercise induced wheezing, EIRSs were weakly associated with EIB in both groups with a large proportion of false positive results. PMCID: PMC3124891. PMID: 21747865

Nakik D, Loš kovska S, Trajkovik V. Fully connected emergency intervention for the critical home care system. Stud Health Technol Inform. 2011;165:88-93.

Ss. Cyril and Methodius University, Faculty of Electrical Engineering and Information Technologies, Karpos 2 bb. Skopje, Macedonia.drasko_21@yahoo.com

The Critical Home Care System - CHCS, we propose, achieves permanent advising, frequent control appointments and quick reaction to critical conditions by constant remote monitoring of patient's vital signs from the hospital, while staying at his home. Physicians react properly to the developing condition, contacting the patient or a member of the household, or sending an ambulance in an emergency. The CHCS additionally provides constant inspection of the patient's condition to the ambulance doctor in emergency situations and to the urgent centre staff to prepare better for accepting the patient, enabling a fully connected emergency intervention. In this paper we will concentrate on the data flow during the emergency intervention in this highly collaborative system. PMID: 21685591

Nakic D, Loš kovska S. Creating knowledge archive in the internet medical consultant for decision support at the point of care. Stud Health Technol Inform. 2011;169:190-4.

Ss. Cyril and Methodius University Faculty of Electrical Engineering and Information Technologies, Karpos 2 bb. Skopje, Macedonia.drasko_21@yahoo.com

The Internet Medical Consultant - IMC is a knowledge sharing system for physicians. The system's main purpose is to collect and store the communication between its users and to provide easy retrieval of stored information. The system provides access to human generated knowledge at the point of care. Having that kind of knowledge at hand can be very helpful for physicians when they make decisions. This paper describes the process of knowledge capturing, creating and searching the knowledge archive, for final utilisation of that knowledge at point of care. PMID: 21893740 
Pejov L, Ristova M, Soptrajanov B. Quantum chemical study of p-toluenesulfonic acid, $p$-toluenesulfonate anion and the water-p-toluenesulfonic acid complex. Comparison with experimental spectroscopic data. Spectrochim Acta A Mol Biomol Spectrosc. 2011 Jun;79(1):27-34. Epub 2011 Jan 12.

Institute of Chemistry, Faculty of Natural Sciences and Mathematics, Ss. Cyril and Methodius University, Skopje, Republic ofMacedonia. Ijupcop@iunona.pmf.ukim.edu.mk

The 1:1 p-toluenesulfonic acid-water complex, p-toluenesulfonic acid itself and the p-toluenesulfonate anion were studied at HF and B3LYP/6-31+G(d,p) levels of theory. Full geometry optimizations of the aforementioned species reveal non-existence of ionic minima on the explored 1:1 p-toluenesulfonic acid-water complex potential-energy hypersurfaces (PEHSs), implying that two or three p-toluenesulfonate ions (+crystal field) are required to stabilize the ionic $\mathrm{H}(3) \mathrm{O}(+) \ldots \mathrm{C}(6) \mathrm{H}(4)(\mathrm{CH}(3)) \mathrm{SO}(3)(-)$ species found in the crystal structure of $p$-toluenesulfonic acid monohydrate (in fact, oxonium p-toluenesulfonate). Harmonic vibrational analyses of the p-toluenesulfonic acid-water complex as well as of the p-toluenesulfonate anion were used to confirm some of our previous reassignments of bands in the vibrational spectra of p-toluenesulfonic acid monohydrate and several metal p-toluenesulfonates. According to the quantum chemical results, the symmetric $\mathrm{SO}(3)$ bending mode should appear at higher frequencies than the antisymmetric one. A more consistent interpretation of the region of appearance of the $\mathrm{SO}(3)$ stretching modes is proposed which is in excellent agreement with the experimental spectroscopic data. The frequency of the multireference benzenoid $\mathrm{v}(14)(\mathrm{B}(2 \mathrm{u})$ ) mode (the "Kekulé" type vibration) is excellently predicted at the B3LYP level of theory, while the HF methodology performs significantly poorer in this respect. The interaction energies as well as the vibrational frequency shifts of the most relevant modes are also presented for the 1:1 p-toluenesulfonic acid-water complex. The NBO analysis is employed to analyze the charge transfer interaction within the complex. PMID: 21420350

Pereska ZJ, Bozinovska C, Dimitrovski C, Petkovska L, Cibisev A, Jurukov I. Plasma apo/lipoproteins disturbances as a precondition for metabolic syndrome in HCV seronegative heroin addicts. Am J Drug Alcohol Abuse. 2011 May;37(3):196-202.

University Clinic of Toxicology, Skopje, The Former
YugoslavRepublic of Macedonia.perevska@yahoo.com

BACKGROUND: Dyslipidemia in heroin addicts is considered to be a precondition for developing metabolic inducer. (1639.2 +/- 476.9 IU, rFSH vs 2356.4 +/- 955.1 IU, HP-hMG, p <0.001). We received significantly higher average number of oocytes and mature oocytes in the group of r-FSH (oocytes; rFSH v HP-hMG-11.8 +/- 7.1 v10.7 +/- 6.5, $\mathrm{p}=0.028$; mature oocytes: rFSH v HPhMG $9.9+/-6.2$ v8.7+/- $5.5 p=0.009$ ). However, we did not find a significant difference in the use of the COS inductors regarding the clinical pregnancy rate ( $\mathrm{rFSH} v$ HP-hMG $49.5 \%$ vs $48.9 \% \mathrm{p}=0.92$ ) and delivery rate (rFSH vs HP-hMG $42.9 \%$ vs $43.4 \%$ $\mathrm{p}=0.96)$.CONCLUSIONSs: Our study showed that $\mathrm{rFSH}$ is more powerful and more applicable in individualized dosing then HP-hMG and brings better results from COS (more oocytes, more matured oocytes). PMID: 21776876

Pesevska S, Nakova M, Gjorgoski I, Angelov N, Ivanovski K, Nares S, Andreana S. Effect of laser on TNF-alpha expression in inflamed human gingival tissue. Lasers Med Sci. 2012 Mar;27(2):377-81. Epub 2011 Mar 5.

Faculty of Dentistry, University Sts Cyril and Methodius, Vodnjanska 17, 1000, Skopje, Macedonia.

This study sought to evaluate the effect of low-level laser treatment combined with scaling and root planing (SRP) on gingival tissue levels of TNF-alpha in subjects with periodontal disease. Eighty gingival papilla biopsy samples were obtained from 60 patients diagnosed with chronic advanced periodontitis; randomly assigned to three treatment groups $(n=20)$, as well as 20 subjects with no periodontal disease (group A). Group B received SRP on a single quadrant/day for four consecutive days. On day 5, all quadrants were rescaled. Groups C and D received the same treatment as group $B$ plus laser application with the low-level diode laser (630-670 nm, $1.875 \mathrm{~J} / \mathrm{cm}(2)$ ) for five and ten consecutive days, respectively. Papilla biopsies were obtained from subjects and evaluated by ELISA for levels of TNF-alpha. The values in the control group were $5.2 \pm 3.21 \mathrm{pg} / \mathrm{mg}$ and baseline values for the examined groups were $46.01 \pm$ 16.69. Significantly decreased level of TNF-alpha for groups $C$ and $D$ was found after treatment, while group $B$ demonstrated reduction of TNF-alpha of $31.34 \%$. The results of this study show suppression of TNF-alpha in gingival tissue after low-level laser treatment as adjunct to SRP. Data may suggest beneficial anti-inflammatory effects of the laser treatment when used as adjunctive 
periodontal treatment. PMID: 21380536

Petanovski Z, Dimitrov G, Aydin B, Hadzi-Lega M, Sotirovska V, Suslevski D, Saltirovski S, Matevski V, Stojkovska S, Lazarova A, Petanovska E, Balkanov T. Recombinant FSH versus HP-HMG for controled ovarian stimulation in intracitoplasmic sperm injection cycles. Med Arh. 2011;65(3):153-6.

IVF Centre - First Private General Hospital - ReMedika, Skopje, Republic of Macedonia. zpetanovski@yahoo.com

The aim of this study was to make a conclusion about aplicability of two differnet gonadothropins in $\mathrm{COS}(\mathrm{rFSH}$ versus HP-hMG). The primary conclusion for the success as a result of COS are the mean number of retrived oocytes, mature oocytes, fertilization rate, mean number of quality embrios, and criopreverzed embrios. The secondary conclusions were clinical pregnancy rate and delivery rates. METHODS: The study was a retrospective case-control study, . A total of 1238 fresh, non donor, IVF cycles with COS were analyzed, but to minimize the bias, only the first cycle for each patient below 40 yaears old, in that period was analyzed. This selection composed the group of respondents that was analyzed which in total amounted to 760 patients. ( $\mathrm{rFSH}=422, \mathrm{HP}-\mathrm{hMG}=$ 338). The patients underwent COS by long luteal protocol using two differnt inducers of $\mathrm{COS}$ ( $\mathrm{rFSH}$ and $\mathrm{HP}-\mathrm{hMG}$ ). RESULTS: The average starting dose of $\mathrm{rFSH}$ used was significantely lower $(152.7+/$ - 41.1IU), whereas with HMG it was (228.8+/-_68.7 IU, $p=000000)$. The average number of IU gonadothropin used in therapy, statistically highly is significantly lower when r- FSH is used as an inducer. (1639.2 +/- 476.9 IU, rFSH vs $2356.4+/$ - 955.1 IU, HP-hMG, $\mathrm{p}<0.001)$. We received significantly higher average number of oocytes and mature oocytes in the group of r-FSH (oocytes; rFSH v HP-hMG-11.8 +/- $7.1 \mathrm{v}$ $10.7+/-6.5, p=0.028$; mature oocytes: rFSH v HP-hMG $9.9+/-6.2$ v8.7+/- $5.5 p=0.009)$. However, we did not find a significant difference in the use of the COS inductors regarding the clinical pregnancy rate $(\mathrm{rFSH} v$ HP-hMG $49.5 \%$ vs $48.9 \% \mathrm{p}=0.92$ ) and delivery rate (rFSH vs HP-hMG $42.9 \%$ vs $43.4 \%$ $\mathrm{p}=0.96$ ). CONCLUSIONSs: Our study showed that rFSH is more powerful and more applicable in individualized dosing then HP-hMG and brings better results from COS (more oocytes, more matured oocytes). PMID: 21776876

Petlichkovski A, Djulejic E, Trajkov D, EfinskaMladenovska O, Hristomanova S, Kirijas M, Senev A,
Spiroski M. Distribution of killer cell immunoglobulinlike receptor genes in Roma from Republic of Macedonia. Int J Immunogenet. 2011 Dec; 38(6):493-500.

Institute of Immunobiology and Human Genetics, University Ss. Cyril and Methodius, Skopje, Republic of Macedonia.

The aim of this study was to analyze Killer Ig-Like Receptor (KIR) gene polymorphisms in Roma people from Republic of Macedonia. The studied sample consists of 103 healthy unrelated individuals, aged 20-45 years. All individuals are of Roma origin, residents of different geographical regions (Gostivar, Skopje, and Kochani). The population genetics analysis package, Arlequin, was used for analysis of the data. We found that all 16 $\mathrm{KIR}$ genes were observed in the Roma individuals and framework genes (KIR3DL3, KIR3DP1, KIR2DL4, and KIR3DL2) were present in all individuals. The frequencies of other KIR genes were: KIR2DP1 (1), KIR2DL1 (0.961), KIR2DL2 (0.544), KIR2DL3 (0.874), KIR2DL5 (0.311), KIR3DL1 (0.990), KIR2DS1 (0.330), KIR2DS2 (0.553), KIR2DS3 (0.359), KIR2DS4 (0.981), KIR2DS5 (0.291), and KIR3DS1 (0.379). The results of tested linkage disequilibrium (LD) among KIR genes demonstrated that KIR genes present a wide range of linkage disequilibrium. The obtained results for KIR genes and genotype frequencies in Macedonian Roma individuals can be used for anthropological comparisons. PMID: 21955885

Petreska I, Pejov L, Kocarev L. Exploring the possibilities to control the molecular switching properties and dynamics: A field-switchable rotorstator molecular system. J Chem Phys. 2011 Jan 7;134(1):014708.

Institute of Physics, Faculty of Natural Sciences and Mathematics, Ss. Cyril and Methodius University, P.O. Box 162, 1000 Skopje, Republic of Macedonia. irina.petreska@pmf.ukim.mk

A bistable, dipolar stator-rotor molecular systemcandidate for molecular electronics is investigated. We demonstrate that it is possible to control the intramolecular torsional states and dynamics in this system by applying an appropriate additional electric field (instead of biasing one), achieving fine tuning and modulation of the relevant properties. The electric field effects on the quantities responsible for torsional dynamics (potential energy surface, potential barrier height, quantum and classical 
transition probabilities, correlation time, HOMO-LUMO gap) are studied from first principles. Our results indicate that it is possible to artificially stabilize the metastable conformational state of the studied molecule. The importance of this is evident, as the current-voltage characteristics of the metastable state are clearly distinguishable from the current-voltage characteristics of the two stable states. We report for the first time exact calculations related to the possibilities to control the thermally induced stochastic switching, and reduce the noise in a practical application. Thus, we believe that the molecule studied in this paper could operate as a field-switchable molecular device under real conditions. PMID: 21219021

Petreska J, Stefova M, Ferreres F, Moreno DA, TomásBarberán FA, Stefkov G, Kulevanova S, Gil-Izquierdo A. Dietary burden of phenolics per serving of "Mountain tea" (Sideritis) from Macedonia and correlation to antioxidant activity. Nat Prod Commun. 2011 Sep;6(9):1305-14.

Institute of Chemistry, Faculty of Science Sts. Cyril and Methodius University, Skopje, Republic of Macedonia.

This work was afforded from 2 points of view, phytochemical evaluation and relation to antioxidant activity and dietary burden of phenolics of a cup of "Mountain tea", a drink obtained by domestic infusion of Sideritis. Phytochemically, two extraction protocols using water and methanol as solvent were used for comparison. Methanol and boiling water extracts (by domestic infusion procedure) showed that extracts were rich in bound pump with glucose sensor, $24 \mathrm{~h} /$ day; and intermittent CGM group, 13 patients on insulin pump with intermittent glucose sensor, 14 days/month. The following parameters were analyzed: glycosylated hemoglobin ( $\mathrm{HbA1c}$ ), mean blood glucose, insulin requirement (in $\mathrm{IU} / \mathrm{kg} /$ day), weight gain, severe hypoglycemic events, diabetic ketoacidosis, macrosomia, cesarean section, and neonatal hypoglycemia. RESULTS: Both groups achieved good glucose control during their pregnancies $(P<0.05): 6.78 \pm 1.3 \%$ and $6.92 \pm 0.9 \%$ at the beginning of the study compared with $6.14 \pm 0.9 \%$ (constant CGM group) and $6.23 \pm 0.6 \%$ (intermittent CGM group) at the end of the study (last HbA1c before delivery). There was no significant decrease of HbA1c between the two groups. The constant CGM group had a significantly lower A1c in the first trimester compared with the intermittent CGM group. Maternal and fetal outcome did not show a significant difference between the two groups.
CONCLUSIONS: Insulin pump therapy together with constant or intermittent CGM can improve diabetes control and pregnancy outcome in type 1 diabetes. The quality of the glucose profile at conception was the important factor for pregnancy outcome. PMID: 21751889

Petreska J, Stefkov G, Kulevanova S, Alipieva K, Bankova V, Stefova M. Phenolic compounds of mountain tea from the Balkans: LC/DAD/ESI/MSn profile and content. Nat Prod Commun. 2011 Jan;6(1):21-30.

Institute of Chemistry, Faculty of Science, Ss. Cyril and Methodius University, Skopje, Republic of Macedonia.

Twenty-one samples of Sideritis species (S. scardica, S. raeseri, S. taurica, S. syriaca and S. perfoliata) from various locations on the Balkan Peninsula were evaluated for their chemical constituents. Chemical analyses were focused on secondary metabolites, particularly phenolic compounds, which have several roles in the plant physiological processes and have demonstrated significant health beneficial effects. The occurrence of hydroxycinnamic acids, phenylethanoid glycosides and flavonoids has been investigated in taxonomically related taxa of the genus Sideritis. A systematic method for phenolic compounds identification was developed using tandem mass spectrometry coupled to high performance liquid chromatography with diode array detection. Scanning for precursor ions of commonly found phenolics in Sideritis species using LC/MS11 with an ion trap instrument permitted the specific determination of hydroxycinnamic acid derivatives, and phenylethanoid and flavonoid glycosides. Further characterization of each phenolic compound was performed using MS/MS product-ion analysis and common-neutral-loss analysis. This on-line technique allowed identification of three hydroxycinnamic acid derivatives, eight phenylethanoid glycosides, and twenty-four flavonoid glycosides. All the taxa analysed produced very similar phenolic patterns characterized by the presence of 5-caffeoylquinic acid, lavandulifolioside, verbascoside, hypolaetin 7-O-[6"'-Oacetyl]-allosyl $(1 \longrightarrow 2)$ glucoside, apigenin 7-(4"-pcoumaroylglucoside), 4'-O-methylisoscutellarein 7-O[6"'-O-acetyl]-allosyl $(1 \longrightarrow 2)$ glucoside, and minor amounts of isoverbascoside, apigenin 7-O-allosyl(1$>2$ ) glucoside, isoscutellarein 7-O-allosyl-(1->2)-[6"-Oacetyl]-glucoside, hypolaetin 7-O-allosyl-(1—2)-[6"-Oacetyl]-glucoside and 4'-O-methylhypolaetin 7-O-[6"'O-acetyl]-allosyl-(1->2)-[6"-O-acetyl]-glucoside. These results show that the investigated species are 
systematically very closely related. Phenylethanoid glycosides and flavonoid acetylglycosides are dominant and constitute $90 \%$ of the total phenolic compounds compared with hydroxycinnamic acid and flavonoid 7-Oglycosides. Principal component analysis (PCA) was performed for the nature and content of the different compounds to be correlated to the particular Sideritis species and also to the locations. PMID: 21366039

Petrovski G, Dimitrovski C, Bogoev M, Milenkovic T, Ahmeti I, Bitovskal. Is there a difference in pregnancy and glycemic outcome in patients with type 1 diabetes on insulin pump with constant or intermittent glucose monitoring? A pilot study. . Diabetes Technol Ther. 2011 Nov;13(11):1109-13. Epub 2011 Jul 13.

University Clinic of Endocrinology, Diabetes and Metabolic Disorders, Medical Faculty, Skopje, Macedonia.goranp@endocrinology.org.mk

BACKGROUND: The aim of the study is to describe glycemic and insulin outcomes by trimester and maternal and fetal outcome in patients with type 1 diabetes using an insulin pump with constant or intermittent continuous glucose monitoring (CGM). METHODS: Twenty-five women with type 1 diabetes with newly diagnosed pregnancy were treated with insulin pump therapy (Medtronic 722, Medtronic Minimed, Northridge, CA) for at least 1 year. Insulin pump and CGM (Medtronic Paradigm Real-Time) were implemented at least 3 months before conception. Patients were randomized in two groups: constant CGM group, 12 patients on insulin pump with glucose sensor, 24 h/day; and intermittent CGM group, 13 patients on insulin pump with intermittent glucose sensor, 14 days/month. The following parameters were analyzed: glycosylated hemoglobin (HbA1c), mean blood glucose, insulin requirement (in IU/kg/day), weight gain, severe hypoglycemic events, diabetic ketoacidosis, macrosomia, cesarean section, and neonatal hypoglycemia. RESULTS: Both groups achieved good glucose control during their pregnancies $(P<0.05): 6.78 \pm 1.3 \%$ and $6.92 \pm 0.9 \%$ at the beginning of the study compared with $6.14 \pm 0.9 \%$ (constant CGM group) and $6.23 \pm 0.6 \%$ (intermittent CGM group) at the end of the study (last HbA1c before delivery). There was no significant decrease of HbA1c between the two groups. The constant CGM group had a significantly lower A1c in the first trimester compared with the intermittent CGM group. Maternal and fetal outcome did not show a significant difference between the two groups. CONCLUSIONS: Insulin pump therapy together with constant or intermittent CGM can improve diabetes control and pregnancy outcome in type 1 diabetes. The quality of the glucose profile at conception was the important factor for pregnancy outcome. PMID: 21751889

Plaseski T, Noveski P, Popeska Z, Efremov GD, Plaseska-Karanfilska D. Association Study of SingleNucleotide Polymorphisms in FASLG, JMJDIA, LOC203413, TEX15, BRDT, OR2W3, INSR, and TAS2R38 Genes With Male Infertility. J Androl. 2012 Jul;33(4):675-83. Epub 2011 Oct 20.

Research Center for Genetic Engineering and Biotechnology, Macedonian Academy of Sciences and Arts, Av Krste Misirkov 2, POB 428, 1000 Skopje, Republic of Macedonia. dijana@manu.edu.mk.

Infertility is a major health problem today, affecting about $15 \%$ of couples trying to conceive a child. Impaired fertility of the male factor is causative in $20 \%$ of infertile couples and contributory in up to another 30\%-40\%. Based on association studies, an increasing number of gene polymorphisms have been proposed to modulate the efficiency of spermatogenesis. Here, we have investigated the possible association of 9 singlenucleotide polymorphisms (SNP) in 8 different genesFASLG, JMJDIA, LOC203413, TEX15, BRDT, OR2W3, INSR, and TAS2R38-with male infertility. We analyzed a total of 136 men with idiopathic infertility (60 azoospermic and 76 oligozoospermic) and 161 fertile controls. Our study group included individuals of different ethnic origin: 93 of the infertile men were Macedonians, 32 were Albanians, and 11 were of other origin. The control group was composed of 125 Macedonian and 36 Albanian men. The methodology included multiplex polymerase chain reaction/SNaPshot analyses, followed by capillary electrophoresis on an ABI3130 Genetic Analyzer. Of the 9 SNPs evaluated, 3 are significantly associated $(P<.05)$ with male infertility: SNPs rs5911500 in LOC203413, rs3088232 in BRDT, and rs11204546 in OR2W3. SNP rs5911500 showed the strongest association with infertility among Albanians $(P=.0001)$, whereas rs3088232 was most significantly associated with azoospermia among Macedonians $(P=.0082)$. Moreover, the frequency of co-occurrence of LOC203413 minor T allele with either homozygosity or heterozygosity for the BRDT minor $G$ allele was significantly higher among both azoospermic (6 of 60 [10\%]; $P=.0057$; odds ratio [95\% confidence interval], 8.83 [1.73-45.08]) and oligozoospermic (10 of 76 [13.2\%]; $P=.0002$; odds ratio 
[95\% confidence interval], 12.04 [2.57-56.47]) men in comparison with fertile controls (2 of 161 [1.2\%]). PMID: 22016351

\section{Pluncevic-Gligoroska J, Manchevska S, Antevska V, Bozhinovska L. Electrophysiological assessment of cognitive processes in young healthy adults with different level of physical activity. Med Arh. 2011;65(2):68-72.}

Institute of Medical and ExperimentalPhysiology, Medical Faculty, University Ss Cyril and Methodius, Skopje, Republic of Macedonia. jasnapg@yahoo.com

AIM: Physical activity has been promoted as a factor that has beneficial influence on brain functions, including cognition. The aim of this study was to detect whether subjects with different levels of physical activity (PA) have different electrophysiological response during cognitive paradigm that includes the processes of expectation, attention and learning. MATERIAL AND METHODS: The study comprised 100 subjects, aged between 17 and 28 years, who were divided into three groups according to the level of general physical activity: with low, moderate and high level of PA. Electroexpectogram (EXG) paradigm is a dynamic CNV paradigm in which the registered evoked potential is a neurophysiological measure of the level of attention and cognitive performance during the paradigm. Parameters derived from these tests are the general EXG parameters that refer to the entire paradigm (number of EXG cycles, maximal and minimal amplitude of the CNV potential and reaction time) and specific EXG parameters that refer to the characteristics of each and every EXG cycle, their amplitude and duration (expressed in number of trials). RESULTS: Subjects with high and moderate level of PA created EXG curves with a greater number of cycles than subjects with a low level of PA. The mean value of the number of created EXG cycles (Low PA = 2.27; moderate $P A=2.73$; high $P A=3.8$ ) and maximal amplitude of CNV (Low PA = 9.42 microV; moderate PA $=10.3$ microV; high PA $=10.43$ microV) was not statistically significant in subjects with different level of PA. The participants with a high and a moderate level of PA showed a distinct tendency of decreasing the dimensions of the EXG cycles: after the long and high first cycle, all subsequent cycles gradually shortened in duration (number of trials) and in height (CNV amplitude). The results of this investigation have emphasized the specific EXG parameters as sensitive indices for successful cognitive adaptation in a dynamic electrophysiological setting created by the EXG paradigm. PMID: 21585176

Polazarevska M, Manchevska S, Filipovska A, Gerazova V. Ten-year epidemiological study on suicide attempts in Skopje, Republic of Macedonia. Med Arh. 2011;65(1):38-41.

University Clinic of Psychiatry, University Ss. Cyril \& Methodius, Skopje, R. Macedonia.

The aim of our study was to provide basic epidemiological data on suicide attempts that resulted in admission to the University Clinic of Toxicology and Emergency Medicine in Skopje during a 10-year-period (1999-2008). There is a lack of published information regarding suicide attempts in the Republic of Macedonia.METHODS: Participants were 1683 patients from the territory of Skopje, who attempted suicides and who were hospitalized in the University Clinic of Toxicology and Emergency Medicine in School of Medicine, Skopje during the period of ten years (1999-2008). The following variables were included in the analysis: age, gender, religion, method of suicide attempt and admission date. The results were analyzed with the Statistic for Windows program, release 7.0. RESULTS: A significantly higher number of suicide attempts were registered in females than in males from the territory of Skopje during the period of 1999-2008. Men who attempted suicide were older than women. Women of Christian religion affiliation attempted suicide BACKGROUND: Proximal tubules of the kidney have a dominant function in the excretion of different enzymes in the urine. These enzymes can be used as markers for secondary renal damage under the action of different diseases, medicines, and toxins. The aim of this study was to evaluate the values of alanine aminopeptidase (AAP), gamma-glutamyl transferase (gamma-GT), and beta2 microglobulin (beta2m) in urine of patients with untreated rheumatoid arthritis (RA) and to define the possible association between untreated rheumatoid arthritis and tubular function at the brush border region. METHODS: We used a kinetic assay for AAP, standard methods by the International Federation for Clinical Chemistry (IFCC) for gamma-GT and Microparticle Enzyme Immunoassay (MEIA), (Abbott A(x)SYM System) for the determination of beta $2 \mathrm{~m}$ in urine of 70 participants (35 untreated RA patients and 35 healthy volunteers (HC)). RESULTS: From the total of 35 RA patients, AAP enzymuria was found in 24 patients with test sensitivity (68.57\%), gamma-GT in 16 patients with test sensitivity $(45.71 \%)$, while the presence of urinary 
beta2 $\mathrm{m}$ was found in a very low percentage of cases. Out of 18 rheumatoid factor (RF) negative patients, 14 patients were AAP and 10 patients were gamma-GT positive, while the presence of beta $2 \mathrm{~m}$ in urine was not detected. Among 17 RF positive RA patients, the presence of AAP and gamma-GT was noticed in 10 and 6 patients, respectively, while the presence of beta $2 \mathrm{~m}$ in urine was not detected. CONCLUSIONS: In conclusion, AAP had a higher sensitivity than gamma-GT and beta2m in detection of asymptomatic renal lesions in untreated RA. PMID: 21755819

Selim G, Stojceva-Taneva O, Spasovski G, Georgievska-Ismail L, Zafirovska-Ivanovska B, Gelev S, Dzekova P, Trajcevska L, Trojacanec-Piponska S, Sikole A. Brain natriuretic peptide between traditional and nontraditional risk factors in hemodialysis patients: analysis of cardiovascular mortality in a two-year follow-up. Nephron Clin Pract. 2011;119(2):c162-70. Epub 2011 Jul 8.

University Clinic of Nephrology, Skopje, Republic of Macedonia.gjulsen_selim@yahoo.com

BACKGROUND: The ability of brain natriuretic peptide (BNP) together with other traditional and nontraditional risk factors to predict cardiovascular (CV) mortality in hemodialysis (HD) patients has not been well established. The aim of this prospective study was to determine the predictive cutoff values of baseline measurement of BNP along with the known CV disease risk factors to predict all-cause and CV mortality in HD patients. METHODS: BNP concentration before HD was measured in 125 prevalent HD patients (age $53.0 \pm 13.5$ years, HD vintage $75.2 \pm 61.0$ months). In addition, several traditional CV risk factors (blood pressure, dyslipidemia, diabetes mellitus, body mass index, left ventricular hypertrophy) and uremia/dialysis-related CV risk factors (anemia, calcium and phosphate impairment, malnutrition, inflammation, ultrafiltration, HD duration, Kt/V) were examined. RESULTS: During the 2-year follow-up, we lost 28 out of 125 patients (22.5\%), with CV disease $(65.7 \%)$ being the main cause of mortality. The cutoff point for BNP, as predictor of the clinical outcome, according to the ROC curve was $1,194 \mathrm{pg} / \mathrm{ml}$ for $\mathrm{CV}$ mortality with sensitivity and specificity of 63 and $65 \%$, respectively (AUC 0.61 and confidence interval $(\mathrm{CI})$ 95\% 0.47-0.75). Kaplan-Meier analysis showed that allcause (log-rank, $p=0.002$ ) and CV mortality (log-rank, $p=0.001$ ) were the cause of a significantly lower survival in patients with a mean BNP $>1,200 \mathrm{pg} / \mathrm{ml}$. The univariate
Cox regression analysis found the following factors to be predictors of all-cause mortality: hemoglobin (<110 g/l), phosphorus $(>1.78 \mathrm{mmol} / \mathrm{l})$, albumin $(<40 \mathrm{~g} / \mathrm{l})$, C-reactive protein (CRP e" $10 \mathrm{mg} / \mathrm{l})$, BNP (>1,200 pg/ml) and cardiac ejection fraction (d" $55 \%$ ). The multivariate Cox regression analyses demonstrated that only CRP e" 10 $\mathrm{mg} / \mathrm{l}$ with a hazard ratio (HR) 6.82 (Cl 95\% 1.86-24.9, p $=0.004)$ and BNP >1,200 pg/ml with HR 5.79 (Cl 95\% 1.58-21.3, $p=0.004)$ were predictors of all-cause mortality. BNP >1,200 pg/ml with HR 13.52 (Cl 95\% 1.68-108.9, $p=0.014$ ) was found to be an even stronger predictor of CV mortality than CRP e" $10 \mathrm{mg} / \mathrm{l}$ with HR 6.53 (Cl 95\% 1.35-31.6, $\mathrm{p}=0.020)$. CONCLUSIONS: Our study pointed out that BNP $>1,200 \mathrm{pg} / \mathrm{ml}$ as a marker of cardiac dysfunction and CRP e" $10 \mathrm{mg} / \mathrm{l}$ as a marker of inflammation identify HD patients at increased risk of CV mortality. PMID: 21757955

\section{Shosholcheva M, Gjorgjev D, Tozija F. Attitude of the Macedonian intensivists regarding withdrawal of therapy in intensive care patients: curriculum for policy development. Med Arh. 2011;65(6):339-42.}

University Clinic of Surgery “St. Naum Ohridski”, Skopje, Macedonia.sosolceva@hotmail.com

Ethical confusion regarding withdraw of therapy led to the aim of the study in which the knowledge and attitude of the Macedonian Intensive Care Unit (ICU) doctors and their impact on decision making process were assessed.METHODS: Knowledge, Attitude and Practice (KAP) study has been conducted on a national sample of 217 ICU doctors (response rate 83.87\%), applying restructured EURELD 2002 questionnaire as study instrument. CHI-square test was used for cross tabulations. RESULTS: 103 responders were females and 79 males with mean age 40, 2 years +/- 3 y. Significant percent of the doctors didn't know what is withdraw of therapy, chi-square $34.47(p<0.0001)$ and for most there was no difference between withdraw of therapy and euthanasia, chi-square $41.482(p<0.0001)$. Most of doctors didn't have any formal training (67\%) and didn't know whether they had experience with withdraw or withhold. Similarly to other countries, for significantly higher percentage of the Macedonian intensivists patient's wishes and patient autonomy have to be main criteria for decision. Significantly higher group of doctors $(p<0.0001)$ would prefer to leave their own advanced directives. CONCLUSIONS: Legal principles in end of life care must be established in the country. Courts should have drawn a distinction between 
intentionally causing a patient's death (euthanasia) and allowing a patient to die as a result of the withdrawal of life support treatment. There is a need of additional improvement of postgraduate curriculum and continuous professional development of ICU doctors working with end-of-life patients. PMID: 22299294

Simonovska N, Chibishev A, Bozinovska C, Grcevska L, Dimitrovski K, Neceva V. Evaluation of circulating immune complexes and antiphospholipid antibodies (anti beta 2 glycoprotein 1) in heroin addicts and their clinical significance. Med Arh. 2011;65(6):3246.

University Clinic of Toxicology, Clinical Centre, Skopje, R. Macedonia.

INTRODUCTION: Earlier studies have reported that heroin might cause the structural and antigen changes on numerous tissues, organs and subsequent development of autoimmune reactions (production of antibodies and creation of immune complexes) as a result the immunotoxic effect of heroin. The aims of our study were to: a) Evaluate $\mathrm{CIC}$ and antibeta2GP1 in heroin addicts; b) Correlate between the values of the obtained CIC and antibeta2GP1 (stratified by the duration and route of heroin application); c) Compare the $\mathrm{CIC}$ and antibeta2GP1 in heroin addicts and the control group and d) Assess the clinical importance of $\mathrm{CIC}$ and antibeta2GP1 in heroin addicts. PATIENTS AND METHODS: This was a cross-sectional study performed at the University Clinic of Toxicology and the Institute of Transfusiology, Skopje, Republic of Macedonia. Patients referred to the Clinic for clinical examinations who met the inclusion criteria were analyzed. Protocol for work was the following: 1.) detailed anamnestic data, 2.) a whole set of laboratory biochemical blood and urine analyses, 3.) examination with the Schiller's twelvechannel ECG; 4.) toxicological analyses for opioids in a urine sample; circulating immune complexes and 5.) antiphospholipid antibodies (antibeta2GP1, fractions: $\lg A$, IgG, IgM). The obtained results were statistically analyzed. RESULTS: We included 37 heroin addicts and a control group of 27 healthy subjects. Male abusers predominated over female in-28 (76\%) subjects; mean age being $26+/-5.06$. The results which refer to the increased values of circulating immune complexes have shown a high statistically significant dominance of heroin addicts, in comparison with the control group $(p<0.01)$ and increased values above the reference ones of IgG antibeta2GP1, alone in the group of intravenous heroin abusers $(p<0.025)$. The mean duration of the heroin use in intravenous abusers was $6.21+/-3.25$ years, whereas in those snorting heroin was $5.15+/-2.26$ years. Duration of heroin application was in a positive correlation with IgG antibeta2GP1 ( $p=0.35)$. CONCLUSIONS: Our data showed that heroin-dependent patients in our study had increased values of circulating immune complexes and changes in IgG and IgM antibeta2GP1 with significantly increased values of IgG antibeta2GP1 in the intravenous heroin abusers. The duration of heroin application is in direct proportional relationship with IgG antibeta2GP1. Heroin addicts had significantly higher values of circulating immune complexes and statistically significant difference in IgG antibeta2GP1, in comparison with the control group. Changes in the fractions of antibeta2GP1 and CIC suggest a possible relation with the somatic changes found in heroin addicts (i.e. thrombocytopenia, reduced renal clearance, etc). PMID: 22299289

Smilkov D, Kocarev L. Analytically solvable processes on networks. Phys Rev E Stat Nonlin Soft Matter Phys. 2011 Jul;84(1 Pt 2):016104. Epub 2011 Jul 18.

Macedonian Academy for Sciences and Arts, Skopje, Macedonia.dsmilkov@cs.manu.edu.mk

We introduce a broad class of analytically solvable processes on networks. In the special case, they reduce to random walk and consensus process, the two most basic processes on networks. Our class differs from previous models of interactions (such as the stochastic Ising model, cellular automata, infinite particle systems, and the voter model) in several ways, the two most important being (i) the model is analytically solvable even when the dynamical equation for each node may be different and the network may have an arbitrary finite graph and influence structure and (ii) when local dynamics is described by the same evolution equation, the model is decomposable, with the equilibrium behavior of the system expressed as an explicit function of network topology and node dynamics. PMID: 21867254

Spasovski D, Masin-Spasovska J, Nada M, Calovski J, Sandevska E, Osmani B, Sotirova T, Balkanov S, Dukovski D, Ljatifi A, Spasovski G. Diagnostic value of brush border enzymes of the proximal renal tubules in rheumatoid arthritis. Clin Lab. 2011;57(5-6):30514. 
Department of Rheumatology, University Clinical Center, Skopje, R. Macedonia. drspasovski@yahoo.co.uk

BACKGROUND: Proximal tubules of the kidney have a dominant function in the excretion of different enzymes in the urine. These enzymes can be used as markers for secondary renal damage under the action of different diseases, medicines, and toxins. The aim of this study was to evaluate the values of alanine aminopeptidase (AAP), gamma-glutamyl transferase (gamma-GT), and beta2 microglobulin (beta2m) in urine of patients with untreated rheumatoid arthritis (RA) and to define the possible association between untreated rheumatoid arthritis and tubular function at the brush border region. METHODS: We used a kinetic assay for AAP, standard methods by the International Federation for Clinical Chemistry (IFCC) for gamma-GT and Microparticle Enzyme Immunoassay (MEIA), (Abbott A(x)SYM System) for the determination of beta2 $m$ in urine of 70 participants (35 untreated RA patients and 35 healthy volunteers (HC)). RESULTS: From the total of $35 \mathrm{RA}$ patients, AAP enzymuria was found in 24 patients with test sensitivity (68.57\%), gamma-GT in 16 patients with test sensitivity (45.71\%), while the presence of urinary beta $2 \mathrm{~m}$ was found in a very low percentage of cases. Out of 18 rheumatoid factor (RF) negative patients, 14 patients were AAP and 10 patients were gamma-GT positive, while the presence of beta $2 \mathrm{~m}$ in urine was not detected. Among 17 RF positive RA patients, the presence of AAP and gamma-GT was noticed in 10 and 6 patients, respectively, while the presence of beta $2 \mathrm{~m}$ in urine was not detected. CONCLUSIONS: In conclusion, AAP had a higher sensitivity than gamma-GT and beta2m in detection of asymptomatic renal lesions in untreated RA. PMID: 21755819

Spasovski G, Ortiz A, Vanholder R, El Nahas M. Proteomics in chronic kidney disease: The issues clinical nephrologists need an answer for. Proteomics Clin Appl. 2011 Jun;5(5-6):233-40.

University Department of Nephrology, Skopje, Macedonia.gspas@sonet.com.mk

A growing number of patients are recognised to have chronic kidney disease (CKD). However, only a minority will progress to end-stage renal disease requiring dialysis or transplantation. Currently available diagnostic and staging tools frequently fail to identify those at higher risk of progression or death. Furthermore within specific disease entities there are shortcomings in the prediction of the need for therapeutic interventions or the response to different forms of therapy. Kidney and urine proteomic biomarkers are considered as promising diagnostic tools to predict CKD progression early in diabetic nephropathy, facilitating timely and selective intervention that may reduce the related health-care expenditures. However, independent groups have not validated these findings and the technique is not currently available for routine clinical care. Furthermore, there are gaps in our understanding of predictors of progression or need for therapy in non-diabetic CKD. Presumably, a combination of tissue and urine biomarkers will be more informative than individual markers. This review identifies clinical questions in need of an answer, summarises current information on proteomic biomarkers and CKD, and describes the European Kidney and Urine Proteomics initiative that has been launched to carry out a clinical study aimed at identifying urinary proteomic biomarkers distinguishing between fast and slow progressors among patients with biopsy-proven primary glomerulopathies. PMID: 21538916

Spasovski G, Zdravkovska V, Zabzun M, Antarorov R, Ivanovski K, Janakievska P, Neskovski J, KarcevaSarajlia E, Panova B, Petrovska T, Zulbeari L, MasinSpasovska J, Taleska-Matovska N, Gelev S. Achievements in CKD-MBD guidelines targets: is there a progress in the implementation practice? Int Urol Nephrol. 2011 Dec 16. [Epub ahead of print]

Department of Nephrology, Medical Faculty, University of Skopje, Vodnjanska 17, 1000, Skopje, Republic of Macedonia,gspas@sonet.com.mk.

BACKGROUND: Guidelines should help the practicing nephrologists to reduce the variability in diagnostic and treatment strategies, and achieve the best possible patients' outcomes. The aim of our study was to look at the treatment strategies and the shortcomings in the implementation of the chronic kidney disease mineral and bone disorder (CKD-MBD) KDOQI guidelines in dialysis units across the Republic of Macedonia in 2009, and to analyze trends with regard to our previous analysis from 2005. METHODS: A questionnaire was sent in 2009 to all dialysis units in our country for data concerning CKD-MBD in dialysis patients. This study included 742 patients, comparable with the reply we got on the same our 2005 survey, with a total of 588 patients. We collected the last 6 months mean values of biochemical parameters [calcium $(\mathrm{Ca})$, phosphate $(\mathrm{P})$, and intact parathyroid hormone (iPTH)], as well as treatment data including dialysate $\mathrm{Ca}$ concentration, phosphate binding agents, 
and vitamin D doses. RESULTS: The majority of patients in both surveys had values within the target ranges for all

Spiroski I, Dimitrovska Z, Gjorgjev D, Mikik V, Efremova-Stefanoska V, Naunova-Spiroska D, Kendrovski V. Nutritional status and growth parameters of school-age Roma children in the Republic of Macedonia. Cent Eur J Public Health. 2011 Jun;19(2):102-7.

Institute of Public Health of the Republic of Macedonia, Skopje, Republic of Macedonia. igor.spiroski@gmail.com

Main objective of the study was to assess the nutritional status of school age Roma children in Macedonia in order to detect precursors of possible health risks at an early age. The study was designed as a comparative case control study. Study group consisted of 229 Roma school children from the 1 st and 272 from the 5th grade residing in different towns in Macedonia. The control group was recruited from other than Roma ethnic background and consisted of 283 children attending 1st and 356 children attending 5th grade. Every participant was measured for his/hers body height and weight. The t-test and Chi square (Chi2) were applied to test statistical significance of variables. The WHO's AnthroPlus software was applied to assess growth parameters and population at risk. There were significant differences in values of the body weight $(p=0.001)$ and height $(p=$ 0.001 ) between Roma and non-Roma children attending the 1st grade of primary school. Weight-for-age, heightfor-age and BMI-for-age indexes of the 1st grade children significantly differred in in the same intervals of $\mathrm{SD}(>$ or $=-2 \mathrm{SD}$ and $<-1 \mathrm{SD} ;>$ or $=-1 \mathrm{SD}$ and median; $>+1 \mathrm{SD}$ and $<\mathrm{or}=+2 \mathrm{SD}$; between Roma and non-Roma 5th graders. Anthropometric parameters of nutritional status of Roma children in Macedonia are significantly different than those of their non-Roma peers. Their health risks are predominantly related to underweight. The parameters related to health risks of overweight or obesity are lower in Roma than in non-Roma children. PMID: 21739902

Stanoev A, Smilkov D, Kocarev L. Identifying communities by influence dynamics in social networks. Phys Rev E Stat Nonlin Soft Matter Phys. 2011 Oct;84(4 Pt 2):046102. Epub 2011 Oct 6.

Macedonian Academy for Sciences and Arts, Skopje, Macedonia. astanoev@cs.manu.edu.mk

Communities are not static; they evolve, split and merge, appear and disappear, i.e., they are the product of dynamical processes that govern the evolution of a network. A good algorithm for community detection should not only quantify the topology of the network but incorporate the dynamical processes that take place on the network. We present an algorithm for community detection that combines network structure with processes that support the creation and/or evolution of communities. The algorithm does not embrace the universal approach but instead tries to focus on social networks and model dynamic social interactions that occur on those networks. It identifies leaders and communities that form around those leaders. It naturally supports overlapping communities by associating each node with a membership vector that describes the node's involvement in each community. This way, in addition to the overlapping communities, we can identify nodes that are good followers of their leader and also nodes with no clear community involvement that serve as proxies between several communities and that are equally as important. We run the algorithm for several real social networks which we believe represent a good fraction of the wide body of social networks and discuss the results, including other possible applications. PMID: 22181222

Stefkov G, Kulevanova S, Miova B, DinevskaKjovkarovska S, Mø Igaard P, Jäger AK, Josefsen K. Effects of Teucrium polium spp. capitatum flavonoids on the lipid and carbohydrate metabolism in rats. Pharm Biol. 2011 Sep;49(9):885-92. Epub 2011 May 27.

Faculty of Pharmacy, Vodnjanska, Skopje, Macedonia. gstefkov@yahoo.com

CONTEXT: The main objective of the study was to investigate the biochemical mechanism of the antidiabetic activities of the dry extracts of Teucrium polium L. ssp. capitatum (L.) Arcangeli (Lamiaceae), from Republic of Macedonia, traditionally used to treat diabetes. MATERIALS AND METHODS: Aerial parts of the plant were extracted in alcohol and freeze- or spray-dried, analyzed by high performance liquid chromatography (HPLC) and examined for insulinotropic effect in INS-1E cells in vitro. Their effect on blood glucose, lipids and carbohydrate-related enzymes was tested in normo-and streptozotocin hyperglycemic rats. RESULTS AND DISCUSSION: HPLC analyses revealed several flavonoids: luteolin, apigenin, cirsiliol, diosmetin, cirsimaritin and cirsilineol as both free aglycons and glycosides. The extract and mixture of commercial 
flavonoids showed a distinct insulinotropic effect on INS$1 \mathrm{E}$ cells at $500 \mu \mathrm{g} / \mathrm{ml}$. Intragastric (i.g.) administration of identical doses of the extract $(125 \mathrm{mg} / \mathrm{kg})$ in both normoand hyperglycemic rats was more efficient in lowering the blood glucose than intraperitoneal injection (35\% vs. $24 \%$ reduction) with highest effect (50\% reduction) $8 \mathrm{~h}$ after administration. After 10 days of treatment, the magnitude of the effect was comparable to i.g. administration of $2.5 \mathrm{mg} / \mathrm{kg}$ of glibenclamide (38\% reduction). No effect was seen on blood lipid profiles. In OGTT (oral glucose tolerance test), the extract lowered blood glucose levels by $\sim 35 \%$. The treatment reduced hepatic glycogen and tended to normalize the activity of gluconeogenic enzymes. CONCLUSION: The results demonstrate that examined plant extracts contain flavonoids with insulinotropic and antihyperglycemic effects. PMID: 21619454

\section{Stevceva L. Toll-like receptor agonists as adjuvants for HIV vaccines. Curr Med Chem. 2011;18(33):5079-82.}

Faculty of Medicine, University Goce Delcev, Stip, Macedonia, Krste Misirkov BB, P.O. Box 20, Stip, Macedonia. Istevceva@yahoo.com

Toll-like receptors (TLRs) are pattern-recognition receptors responsible for detecting invading pathogens. About 13 TLRs are currently known to be expressed (see Table 1). TLR2 detects lipotechoic acid and bacterial lipoproteins, TLR4 recognizes LPS, TLR5, flagellin and TLR3 detects double-stranded RNA. The unmethylated CPG DNA of bacteria and viruses is detected by TLR9. TLR7 recognizes single-stranded RNA of viruses. TLR 11 in mice recognizes profillin from Toxoplasma gondii. Binding to TLRs expressed on dendritic cells (DCs) can trigger adaptive immune responses and DCs thus serve as a bridge between innate and adaptive immunity. In HIV, it has been shown that polymorphism of the TLR9, 4, 7 and 8 plays a role in disease progression and viral load. In addition, several researchers began investigating using TLR agonists as adjuvants for HIV vaccine candidates. TLR3 has shown good results if used with vaccine proteins selectively delivered to DCs by antibodies to DEC-205/CD205, a receptor for antigen presentation. TLR7/8 and TLR9 agonists enhanced immune responses if conjugated to the vaccine protein. A triple combination of TLR2/6, -3 , and -9 agonists and IL-15 synergistically up regulated immune responses to vaccine formulated as recombinant MVA viruses expressing SIVmac239 Gag, Pol, Env and Rev, Tat, Nef.
These and other studies are just beginning to unravel the potential of TLRs agonists and much more and broader research is needed in order to revitalize the field of HIV vaccines. PMID: 22050755

Stojanovska Z, Januseski J, Boev B, Ristova M. Indoor exposure of population to radon in the FYR of Macedonia. Radiat Prot Dosimetry. 2012 Jan;148(2):162-7. Epub 2011 Mar 15.

Institute for Public Health of RM, Laboratory for Radioecology Skopje, Skopje, FYR of Macedonia. stojanovskazdenka@gmail.com

The authors present the results of a year-long survey of the indoor radon concentration levels in the FYR of Macedonia. A total number of 437 dwellings in eight statistical regions were subject to radon concentration measurements by using CR-39 track detectors. The annual mean indoor radon concentration in each measuring site was estimated from the four individual measurements with 3 months duration. The measuring period was from December 2008 to December 2009. The distribution of the results was nearly log-normal. The arithmetic and geometric mean values of the annual mean value of radon concentration were estimated to be SLC22A12 encoding the urate transporter protein URAT1 and correlate these genetic findings with functional characterization. Urate handling was determined using uptake experiments in HEK293 cells. This data highlights the importance of the URAT1 renal urate transporter in determining serum urate concentrations and the clinical phenotypes, including nephrolithiasis, that should prompt the clinician to suspect an inherited form of renal hypouricaemia. PMCID: PMC3241677; PMID: 22194875

\section{Talevska V, Stefanovski B. Mental illness and homicide-prevention of recidivism. Acta Clin Croat. 2011 Dec;50(4):501-8.}

Demir Hisar Psychiatric Hospital, University Department of Psychiatry, School of Medicine, Skopje, Macedonia. talevskav@yahoo.com.mk

We hypothesized that the integration of forensic psychiatrists and the forensic system into the general stream of mental health should lead to better reintegration of forensic patients into the society. The aims of the study were to explore the link between violence, murder, psychiatric disorders and other variables, and to suggest a mode of prevention of criminal recidivism. This 
investigation provided a more reflective profile of mentally ill persons convicted of murder, hospitalized in Psychiatric Hospital in Demir Hisar in Macedonia between 2007 and 2009. Study results indicated the offender with severe mental illness incarcerated for murder in Demir Hisar Psychiatric Hospital to be predominantly suffering from a mood disorder, to be a male with secondary school education, and to have significant intimate and family relationships characterized by rage as a frequently mentioned motive for murder. On committing homicide, they frequently used firearm or sharp objects. The offenders lived in dysfunctional families, had extensive histories of substance abuse and criminal activity before their murder conviction, and received inadequate treatment for their mental disorder and substance abuse. We suggest that the offenders (murderers) continue their treatment in mental health forensic services upon completing their obligatory treatment at a psychiatric hospital. PMID: 22649880

Taseska M, Jaæimoviæ R, Stibilj V, Stafilov T, Makreski P, Jovanovski G. Determination of trace elements in some copper minerals by k0-neutron activation analysis. Appl Radiat Isot. 2012 Jan;70(1):35-9. Epub 2011 Jul 23.

Institute of Chemistry, Faculty of Science, SS. Cyril and Methodius University, P.O. Box 162, MK-1001 Skopje, Macedonia.

Trace element contents in two copper minerals [brochantite $[\mathrm{Cu}(4) \mathrm{SO}(4)(\mathrm{OH})(6)]$ and native $\mathrm{Cu}$ ] using $\mathrm{k}(0)$-NAA were determined before and after quantitative removal of copper. The distribution of 44 elements in the studied minerals was investigated. An important advantage of the proposed method is the possibility to determine the content of several elements (Al, Dy, Mg, $\mathrm{Mn}$ and $\mathrm{V}$ ) via their short-lived nuclides after the electrolytic removal of Cu due to the elimination of matrix interferences. PMID: 21816618

Tasic V, Lozanovski VJ, Ristoska-Bojkovska N, Sahpazova E, Gucev Z. Nephrotic syndrome occurring during tiopronin treatment for cystinuria. Eur J Pediatr. 2011 Feb;170(2):247-9. Epub 2010 Oct 6.

University Children's Hospital, Medical School Skopje, 17 Vodnjanska, 1000 Skopje, Macedonia. vtasic2003@gmail.com
Cystinuria is an autosomal recessive disorder characterized with abnormal tubular reabsorption of cystine and dibasic amino acids leading to cystine urolithiasis. The classical form is caused by mutations in the SLC3A1 gene (OMIM 220100). The cornerstone of the treatment is high hydration and alkalization of the urine to achieve urine $\mathrm{pH}$ between 7.0 and 7.5 , at which point, cystine solubility in the urine is optimal. These measures very often fail, and thus addition of sulfhydryl agents like penicillamine and tiopronin (mercaptopropionyl glycine) is recommended. Herein, we report a 3-year-old boy with cystinuria resulting in recurrent nephrolithiasis requiring surgery and extracorporeal shock wave lithotripsy. Nine months after introduction of tiopronin, the boy manifested generalized edema, oliguria, and biochemical indices of nephrotic syndrome. Tiopronin was withdrawn, and the boy was given only supportive treatment. Within 10 days, he entered into clinical and biochemical remission. Pediatricians should be aware of this adverse effect of tiopronin, and therefore, testing of the urine with strips or sulfosalicylic acid at least once weekly at home may be very helpful for early detection of proteinuria. PMID: 20924604

Tasic V, Pota L, Gucev Z. Recurrent urinary tract infections in an infant with antenatal Barter syndrome. World J Pediatr. 2011 Feb;7(1):86-8. Epub 2010 Feb 1.

Department of Pediatric Nephrology, University Children's Hospital, Skopje, Macedonia. vtasic2003@gmail.com

BACKGROUND: antenatal variant of Bartter syndrome is characterized by a history of polyhydramnios, premature birth, metabolic alkalosis, hypokalemia, polyuria and renal salt wasting. In this report we present a premature female baby with antenatal Barter syndrome who had three episodes of urinary tract infection (UTI), without evidence for congenital anomaly of the kidneys or urinary tract. METHODS: antenatal Bartter syndrome was diagnosed according to the standard criteria. Ultrasound scan and voiding cystourethrography were performed to exclude congenital anomaly of the kidneys and urinary tract. RESULTS: the baby presented with early hyperkalemia and acidosis. The typical biochemical features of the Bartter syndrome were observed in the second month. Despite appropriate treatment she had persistent hypercalciuria. The clinical course was complicated with recurrent episodes of febrile UTIs. 
Urinary tract system imaging did not demonstrate congenital anomalies. She finally died of severe dehydration, acidosis and renal failure. CONCLUSION: since no congenital anomaly of the kidneys or urinary tract was demonstrated in our patient, we believe that severe, persistent hypercalciuria is the most important risk factor for development of recurrent UTIS. PMID: 20127218

Tasic V, Lozanovski VJ, Gucev Z, Blau N, Cheong HI, Sayer JA. Failure to thrive and nephrolithiasis in a boy with congenital cyanotic heart anomaly. Pediatr Nephrol. 2011 Dec;26(12):2153-7. Epub 2011 Mar 1.

Department of Pediatric Nephrology, University Children's Hospital, Medical School Skopje, 17 Vodnjanska, 1000, Skopje, Macedonia. vtasic2003@gmail.com

Abstract not available. PMID: 21360111

Tasic V, Lozanovski VJ, Korneti P, RistoskaBojkovska N, Sabolic-Avramovska V, Gucev Z, Ludwig M. Clinical and laboratory features of Macedonian children with OCRL mutations. Pediatr Nephrol. 2011 Apr;26(4):557-62. Epub 2011 Jan 20.

University Children's Hospital, Medical School Skopje, Skopje, Macedonia.vtasic2003@gmail.com

OCRL mutations, which are a hallmark of Lowe syndrome, have recently been found in patients with isolated renal phenotype (Dent-2 disease). In this report, we describe clinical and laboratory features in five Macedonian children with mutations in the OCRL gene. Children with a clinical diagnosis of Lowe syndrome or Dent disease underwent complete neurological and ophthalmological examination, imaging of the kidney and urinary tract, assessment of renal tubular function, and mutation analysis of the OCRL gene. Two children (18 months and 11 years, respectively) were diagnosed with Lowe syndrome on the basis of congenital cataracts, severe psychomotor retardation, and renal dysfunction. Both children had low molecular weight proteinuria (LMWP) and hypercalciuria, but not Fanconi syndrome. The older one had bilateral nephrolithiasis due to associated hypocitraturia and mild hyperoxaluria. Three children with asymptomatic proteinuria were diagnosed with Dent2 disease; none had cataracts or neurological deficit. One child showed mild mental retardation. All had LMWP, hypercalciuria, and elevated enzymes (creatine phosphokinase, lactic dehydrogenase). All three children had an abnormal Tc-99m DMSA scan revealing poor visualization of the kidneys with a high radionuclide content in the bladder; none had nephrolithiasis or nephrocalcinosis. In conclusion, children with OCRL mutations may present with very mild phenotype (asymptomatic proteinuria with/without mild mental retardation) or severe classic oculocerebrorenal syndrome of Lowe. Elevated enzymes and abnormal results on the Tc-99m DMSA scan may be useful indicators for Dent-2 disease. PMID: 21249396

Tasic V, Hynes AM, Kitamura K, Cheong HI, Lozanovski VJ, Gucev Z, Jutabha P, Anzai N, Sayer JA. Clinical and functional characterization of URAT1 variants. PLoS One. 2011;6(12):e28641. Epub 2011 Dec 16.

Medical School, University Children's Hospital, Skopje, Macedonia.

Idiopathic renal hypouricaemia is an inherited form of hypouricaemia, associated with abnormal renal handling of uric acid. There is excessive urinary wasting of uric acid resulting in hypouricaemia. Patients may be asymptomatic, but the persistent urinary abnormalities may manifest as renal stone disease, and hypouricaemia may manifest as exercise induced acute kidney injury. Here we have identified Macedonian and British patients with hypouricaemia, who presented with a variety of renal symptoms and signs including renal stone disease, hematuria, pyelonephritis and nephrocalcinosis. We have identified heterozygous missense mutations in SLC22A12 encoding the urate transporter protein URAT1 and correlate these genetic findings with functional characterization. Urate handling was determined using uptake experiments in HEK293 cells. This data highlights the importance of the URAT1 renal urate transporter in determining serum urate concentrations and the clinical phenotypes, including nephrolithiasis, that should prompt the clinician to suspect an inherited form of renal hypouricaemia. PMCID: PMC3241677. PMID: 22194875

Topuzoski S, Janicijevic L. Diffraction characteristics of optical elements designed as phase layers with cosine-profiled periodicity in the azimuthal direction. J Opt Soc Am A Opt Image Sci Vis. 2011 Dec 1;28(12):2465-72.

Institute of Physics, Faculty of Natural Sciences and 
Mathematics, University Saints Cyriland Methodius, Skopje, Republic of Macedonia. suzana_topuzoski@yahoo.com

The article concerns an investigation of the Fresnel diffraction characteristics of two types of phase optical elements under Gaussian laser beam illumination. Both elements provide an azimuthal periodicity of the phase retardation. The first element possesses azimuthal cosine-profiled phase changes deposited on a plane base. The second element is a combination of the first element and a thin phase axicon. The cosine profile of the phase retardation of both diffractive elements produces an azimuthal cosine-profiled modulation on their diffractograms. It destroys the vortex characteristics of their diffraction fields. PMID: 22193260

Tosheska K, Labudovic D, Jovanova S, Jaglikovski B, Alabakovska S. Cholesteryl ester transfer protein, low density lipoprotein particle size and intima media thickness in patients with coronary heart disease. Bosn J Basic Med Sci. 2011 Aug;11(3):169-73.

Department of Medical and Experimental Biochemistry, University "Ss Cyril and Methodius", Skopje, Republic of Macedonia. tosheskatrajkovska@gmail.com

Cholesteryl ester transfer protein (CETP) plays a key role in reverse cholesterol transport and high density lipoprotein (HDL) metabolism. Predominance of small, dense LDL particles is associated with an increased risk of atherosclerosis and coronary heart disease (CHD). The aim of the study was to determine the potential relationship between the CETP concentration and low density lipoprotein (LDL) particle size and their association with intima media thickness (IMT) in patients with CHD. Lipid parameters, CETP concentration and LDL particle size were determined in 100 healthy subjects (control group) and in 100 patients with CHD, aged 43 to 77 years. Plasma CETP concentrations were measured by an enzyme-linked immuno-sorbent assay with two different monoclonal antibodies. LDL subclasses were separated by nondenaturing polyacrilamide $3-31 \%$ gradient gel electrophoresis. CETP concentration was higher in patients compared to controls $(2.02 \pm 0.75 \mathrm{mg} / \mathrm{ml}$ vs. $1.74 \pm 0.63 \mathrm{mg} / \mathrm{ml}, \mathrm{p}<0.01)$. Mean LDL particle size $(\mathrm{nm})$ was significantly smaller in patients than in controls (24.5 \pm 1.1 vs. $26.1 \pm 0.9 ; p<0.001)$. There was no relation between LDL particle size and CETP concentration ( $r=-0.1807, p=0.072)$. Age, diastolic blood pressure, CETP concentration and LDL particle size were independent factors for determing IMT by multiple linear regression analysis. They accounted for $35.2 \%$ of the observed variability in IMT. CETP is not an independent contributor of LDL particle size. CETP might play a role in determining lipoprotein distributions, but did not seem to be the sole factor in the formation of small LDL particles. PMID: 21875419

Vlaski E, Stavric K, Seckova L, Kimovska M, Isjanovska R. Do household tobacco smoking habits influence asthma, rhinitis and eczema among 13-14 year-old adolescents? Allergol Immunopathol (Madr). 2011 Jan-Feb;39(1):39-44. Epub 2010 Sep 22.

Department of Pulmonology and Allergology, University Children's Hospital, Skopje, Republic of Macedonia. vlaskie@sonet.com.mk

BACKGROUND: Although the harmful impact of environmental tobacco smoke on respiratory health in early childhood is well known, its effect in adolescence is still ambiguous. This study aims to examine if parents' and household tobacco smoking habits influence asthma, rhinitis and eczema in early adolescence in The Republic of Macedonia, as a country with a very high rate of household tobacco smoke exposure despite the smoking cessation campaign, and low prevalence rates of asthma, rhinitis and eczema. METHODS: Children aged 13-14 years $(n=3026)$ from randomly selected schools in Skopje, the capital of Macedonia, completed by themselves the standardised International Study of Asthma and Allergies in Childhood (ISAAC) Phase Three written questionnaires on asthma, rhinitis, eczema and potential environmental risk factors. Maternal and paternal tobacco smoking habits and the number of smokers in households were separately correlated to current and ever-diagnosed asthma, rhinitis and eczema by odds ratios (OR, 95\% Cl) with and without adjustments for potential confounders using binary logistic regression. RESULTS: The maternal smoking habit was significantly positively associated only with current night dry cough apart from chest infection (aOR: 1.26; 1.03-1.54; $p=0.026)$. No significant association was observed in relation to the other studied variables with either parental smoking habits or the number of smokers in the household. CONCLUSION: Household tobacco smoking habits were not found to have a significant influence on asthma, rhinitis and eczema in young adolescents. The established results point out the dominant influence of maternal smoking on cough as an unspecific asthma symptom. Copyright (C) 2010 SEICAP. Published by Elsevier Espana. PMID: 20864245 